\title{
Combination therapy with immune checkpoint inhibitors (ICls); a new frontier
}

\author{
Somayeh Vafaei ${ }^{1}$, Angelina O. Zekiy², Ramadhan Ado Khanamir ${ }^{3}$, Burhan Abdullah Zaman ${ }^{4}$, \\ Arman Ghayourvahdat ${ }^{5}$, Hannaneh Azimizonuzi ${ }^{6}$ and Majid Zamani ${ }^{7^{*}}$ (D)
}

\begin{abstract}
Recently, immune checkpoint inhibitors (ICls) therapy has become a promising therapeutic strategy with encouraging therapeutic outcomes due to their durable anti-tumor effects. Though, tumor inherent or acquired resistance to ICls accompanied with treatment-related toxicities hamper their clinical utility. Overall, about $60-70 \%$ of patients (e.g., melanoma and lung cancer) who received ICls show no objective response to intervention. The resistance to ICls mainly caused by alterations in the tumor microenvironment (TME), which in turn, supports angiogenesis and also blocks immune cell antitumor activities, facilitating tumor cells' evasion from host immunosurveillance. Thereby, it has been supposed and also validated that combination therapy with ICls and other therapeutic means, ranging from chemoradiotherapy to targeted therapies as well as cancer vaccines, can capably compromise tumor resistance to immune checkpoint blocked therapy. Herein, we have focused on the therapeutic benefits of ICls as a groundbreaking approach in the context of tumor immunotherapy and also deliver an overview concerning the therapeutic influences of the addition of ICls to other modalities to circumvent tumor resistance to ICls.
\end{abstract}

Keywords: Immune-checkpoint inhibitors (ICls), Tumor microenvironment (TME), Resistance, Combination therapy, Immune cells

\section{Introduction}

During the last two decades, tumor immunotherapy has evolved the clinical management of a diversity of tumors even with undesired prognoses $[1,2]$. As one of the most eminent eras in the context of tumor immunotherapy, immune-checkpoint inhibitors (ICIs) have engendered remarkable therapeutic outcomes as a result of their broad bioactivity across numerous histological tumor types along with their durable anti-tumor impacts [3, 4]. Among the checkpoint-blocking strategies, inhibition of the cytotoxic-T-lymphocyte-associated protein 4 (CTLA-4 or CD152) and also blocking the interfaces between programmed cell death 1 (PD-1 or CD279) and

\footnotetext{
*Correspondence: zamani.m@gmu.ac.ir

${ }^{7}$ Department of Medical Laboratory Sciences, Faculty of Allied Medicine,

Infectious Diseases Research Center, Gonabad University of Medical Sciences, Gonabad, Iran

Full list of author information is available at the end of the article
}

programmed cell death ligand 1 (PD-L1 or CD274 or B7 homolog 1) has gained increasing attention [5]. Due to the substantial homology to the costimulatory molecule CD28, CTLA-4 can bind B7 molecules on antigen-presenting cells (APCs) with much higher affinity and also avidity than CD28, averting the activation of $\mathrm{T}$ cell responses [6]. The evidence regarding the CTLA-4 activities offered the concept that dampening its activities could enable durable T cell responses [7]. Then, accumulating evidence supported the responding notion, and after than much effort was spent to produce ipilimumab, a monoclonal antibody (mAb) targeting human CTLA-4 [8]. Irrespective of inhibition of the costimulation, CTLA-4 inhibitors can also attenuate regulatory $\mathrm{T}$ (Treg) cell recruitment into tumor tissue due to the high expression of CTLA-4 on the surface of Treg [9]. Negative regulation of Tregs population in the tumor microenvironment (TME), in turn, largely improves the infiltration original author(s) and the source, provide a link to the Creative Commons licence, and indicate if changes were made. The images or other third party material in this article are included in the article's Creative Commons licence, unless indicated otherwise in a credit line to the material. If material is not included in the article's Creative Commons licence and your intended use is not permitted by statutory regulation or exceeds the permitted use, you will need to obtain permission directly from the copyright holder. To view a copy of this licence, visit http://creativecommons.org/licenses/by/4.0/. The Creative Commons Public Domain Dedication waiver (http://creativeco mmons.org/publicdomain/zero/1.0/) applies to the data made available in this article, unless otherwise stated in a credit line to the data. 
as well as anti-tumor activities of tumor-infiltrating lymphocytes (TILs), in particular, cytotoxic T lymphocytes (CTL) [10]. On the other hand, the PD-1 functions as a critical immune checkpoint were documented upon detecting its central ligand, PD-L1, which is found on multiple cell types such as tumor cells, immune cells, epithelial cells, and endothelial cells [11]. Similar to CTLA-4, the PD-1is expressed on induced $\mathrm{T}$ cells and contributes to the down-regulation of signaling complicated in antigen recognition by the T cell receptor (TCR) [12]. PD-L1 expression is in association with exposure to interferon- $\gamma$ (IFN- $\gamma$ ) for example following anti-tumor $\mathrm{T}$ helper type 1 (Th1) cell responses, and could ultimately ease tumor cell's escape from $\mathrm{T}$ cell antitumor immunity [13-15]. Like anti-CTLA-4 antibody ipilimumab, PD-1/PD-L1 inhibitors, surrounding nivolumab, pembrolizumab, cemiplimab, atezolizumab, avelumab, and durvalumab have gained approval from United States Food and Drug Administration (FDA) during the last decade (Fig. 1) $[16,17]$. However, tumor resistance to ICIs $[18,19]$ and also treatment-associated toxicities [20] impede their clinical utility. Recent reports have shown that objective response rate (ORR) in melanoma patients treated with PD-1 inhibitors is only $33 \%$, and also more than $70 \%$ of non-small-cell lung carcinoma (NSCLC) patients exhibit no response to ICIs [21]. It has been evidenced that TME in association with other factors supports chronic inflammation, improves immunomodulation, and concomitantly aids pro-angiogenic intratumoral microenvironment, and thereby entices tumor cells evasion from recognition and succeeding elimination by host immunosurveillance [22, 23]. Accordingly, several studies have exhibited that combination therapy with ICIs plus other therapeutic approaches, such as chemotherapy [24-26], radiotherapy [27, 28], cancer vaccines [29-31], anti-angiogenic agents [32-34], HER-2 targeted therapies [35] and also CXCR4 blockade therapy [36, 37] can efficiently circumvent tumor resistance to ICI therapy.

In the present review, we deliver an overview about the therapeutic merits of ICIs as a pioneering tactic in tumor immunotherapy and also discuss recent reports evaluating the combined use of ICIs with other

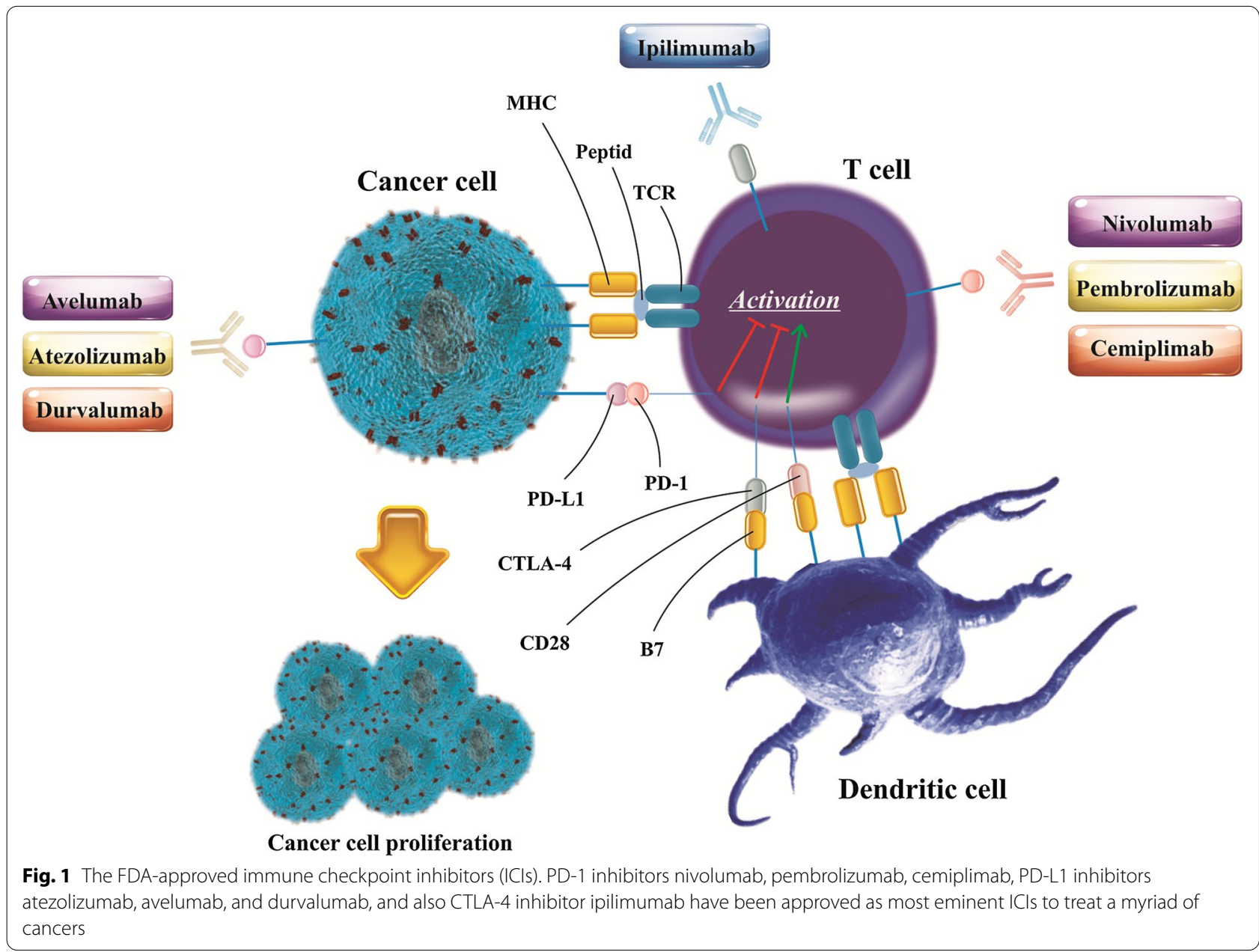


conventional approaches to overcome tumor resistance to ICI, with a particular concentration on last decade in vivo reports.

\section{The rationality of ICls therapy}

Communication between immune checkpoints and their responding ligands abrogates $\mathrm{T}$ cell activation and resultant anti-tumor immunity by targeting a myriad of signaling axes, in particular, phosphatidylinositol-3-kinase (PI3K)/Akt pathway [38]. As a result, NF-kB and mTOR activation and also IL-2 and Bcl-xL expression are negatively affected in activated $T$ cells [39]. Such events eventually hinder physiological immune reactions against tumor-associated antigens (TAAs). Notably, immune checkpoints and the related ligands are mainly upregulated in the TME and also on the surface of tumor cells, and so underlies blockade of anti-tumor immune response $[40,41]$.

As known, CD80 (B7-1) and CD86 (B7-2) co-stimulation by $\mathrm{CD} 28$ delivers vital stimulatory signals, which eases $\mathrm{T}$ cell proliferation and differentiation throughout the induction phase of immunological response [42]. The CTLA-4 co-inhibitory receptor is largely demonstrated on lately activated $T$ cells and creates interfaces with the same ligands as CD28 but with higher affinity [43, 44]. Interrelation between CTLA-4 and CD80/86 impedes $\mathrm{T}$ cell activation by both suppressing the formation of a communication between CD80/CD86 and CD28, and also transmitting suppressive signals $[45,46]$. Structurally, CTLA-4 includes a unique YVKM motif at the cytoplasmic domain, which brings about inhibitory signaling upon interaction with the Src homology 2 domain-containing protein tyrosine phosphatase 2 (SHP2) [7]. CTLA-4 inhibits T-cell responses by cell-intrinsic and extrinsic pathways. Intrinsic events involve the suppression of protein translation and cytokine receptor signaling through the induction of the recruitment of phosphatases and ubiquitin ligases [47]. Besides, cellextrinsic actions comprise the competition for CD28 in binding to $\mathrm{CD} 80 / 86$, the removing $\mathrm{CD} 80 / 86$, secretion of suppressive indoleamine (2,3)-dioxygenase (IDO), and also targeting Treg activities [47]. Other in vivo reports deliver the proof of the hypothesis that CTLA-4 can adjust T-cell infiltration into allografts as well as tumors [48]. Unsurprisingly, elevated levels of CTLA-4 in association with poor prognosis has been found in NSCLC [49-51], breast cancer [52, 53], nasopharyngeal carcinoma [54], small cell lung cancer (SCLC) [55], prostate cancer [56], thymoma [57], melanoma [58, 59], colorectal cancer (CRC) [60], glioblastoma [61] and osteosarcoma [62].

Anti-tumor T cells following acquirement of cytokineproducing and cytolytic effector competencies can undergo additional negative regulation by an interaction between PD-1 on such cells with PD-L1 on tumor cells or tumor-associated antigen-presenting cell (APC) in the TME $[63,64]$. Interaction between PD-L1expressing tumor cells or APC and PD-1 expressing T cells leads ultimately to eliciting signaling by cytoplasmic tail of PD-1, facilitating $T$ cell exhaustion. The cytoplasmic tail of PD-1 includes two tyrosine-based structural motifs, an immunoreceptor tyrosine-based inhibitory motif (ITIM) $(\mathrm{V} / \mathrm{L} / \mathrm{I} / \mathrm{XpYXX} / \mathrm{L} / \mathrm{V})$ and an immunoreceptor tyrosinebased switch motif (ITSM) (TXpYXXV/I) [65]. The PD-1 suppressive activities depend on the ITSM phosphotyrosine, which in turn, potentiates the recruiting SHP-2 and suppressing downstream signaling pathways like CTL-4 $[65,66]$. Various tumors apply this mechanism by upregulation of PD-L1 which often relates to unfavorable prognosis. Further, expression of PD-1 on some tumor cells has also recently been elucidated [67]. Indeed, interfaces between PD-L1 on tumor cells with PD-1 on immune cells sustain immune escape and tumor development more chiefly by suppression of cytotoxic $\mathrm{T}$ lymphocyte (CTL) effector function [68]. Improved expression of PD-L1 on tumors has been validated to intensely correlate with advanced disease state and unfavorable prognosis in melanoma, breast, gastric, ovarian, liver, kidney, pancreatic, and also bladder cancer [68].

Given that ICIs with the goal of targeting CTLA-4, PD-1, or PD-L1 can dampen immune checkpointsinduced inhibitory impacts on $\mathrm{T}$ cells biological processes, making further progress to evolve novel ICIs for broader types of malignancies is urgently justified.

\section{FDA-approved ICls}

\section{CTLA-4 inhibitors}

The monoclonal antibody ipilimumab which targets CTLA-4 has been approved on March 25, 2011, to treat patients with metastatic melanoma [8]. It is also used in combination with nivolumab for the treatment of advanced renal cell carcinoma (RCC) [69], microsatellite instability-high (MSI-H) or mismatch repair deficient (dMMR) metastatic CRC [70], hepatocellular carcinoma (HCC) [71], NSCLC [72], and malignant pleural mesothelioma (MPM) [73]. The most common adverse events correlated with ipilimumab are immune related adverse events (irAEs), and both anti-cancer and irAE reactions. During the last decade, some clinical trials have indicated that monotherapy with ipilimumab $(10 \mathrm{mg} /$ $\mathrm{kg}$ ) in patients with advanced melanoma could result in improved OS rate [74], and a durable objective response [75]. In addition to monotherapy with ipilimumab, this CTLA-4 inhibitor combined nivolumab led to longer progression-free survival (PFS) and a higher objective response rate (ORR) in a phase 3 trial in patients with 
advanced melanoma (NCT01844505) [76]. Importantly, the OS rate at 3 years was $58 \%$ in the nivolumab plus ipilimumab group and $52 \%$ in the nivolumab group, while was $34 \%$ in the ipilimumab group [76]. Besides, irAEs happened in $59 \%$ of the patients in the nivolumab plus ipilimumab group, in $21 \%$ of patients in the nivolumab group, and $28 \%$ of patients in the ipilimumab group [76]. Thereby, combination therapy showed superiority over monotherapy with ipilimumab or nivolumab in terms of efficacy, while a higher rate of the occurrences of irAEs dampens its clinical use [76]. Further, the combination of nivolumab and ipilimumab induced a deep enhancement in proliferation and activation of T cells in MPM patients (NCT03048474) [77]. Patients that responded to treatment with nivolumab plus ipilimumab had low densities of naive CD8 T cells and conversely high densities of effector memory CD8 T cells and granzyme-B and interferon- $\gamma$ producing T cells [77]. Another trial on 108 patients also revealed that monotherapy with nivolumab and also combination therapy with nivolumab plus ipilimumab demonstrated promising anti-tumor activities in relapsed patients with MPM, without unexpected toxicity [73]. Meanwhile, $44 \%$ of patients in the nivolumab group and $50 \%$ of patients in the nivolumab plus ipilimumab group experienced 12-week disease control [73]. As well, a phase 3 trial on patients with advanced NSCLC verified the superiority of combination therapy with nivolumab plus ipilimumab on chemotherapy, as shown by higher median OS rate in combination therapy group than chemotherapy group (17.1 months versus 14.9 months. Meanwhile, the median duration of response (DOR) was 23.2 months with ipilimumab plus nivolumab and 6.2 months with chemotherapy (NCT02477826) [72]. These findings provided clear evidence implying that combination therapy with ipilimumab plus nivolumab has superiority over chemotherapies due to the lower safety concerns and higher activities in NSCLC [72]. The safety and efficacy of combination therapy with nivolumab plus ipilimumab also was indicated in dMMR/ MSI-H metastatic CRC [70]. Accordingly, PFS rates were $76 \%$ (9 months) and 71\% (12 months) and respective OS rates were $87 \%$ and $85 \%$ [70]. Correspondingly, amelioration was observed in patients, such as functioning, symptoms, and quality of life, and also intervention showed manageable ir-AEs [70, 78].

\section{PD-1 inhibitors}

Nivolumab, pembrolizumab, and cemiplimab, wellknown PD-inhibitors, are fully human IgG4 mAb and have demonstrated capable potential to treat advanced melanoma and NSCLC patients [79]. Apart from combination therapy with ipilimumab, monotherapy with nivolumab also is indicated for gastric cancer, and classic
Hodgkin's lymphoma (cHL) therapy [80]. Pembrolizumab has been used for the treatment of patients with metastatic melanoma and NSCLC [81], metastatic bladder cancer [82], head and neck squamous cell carcinomas (HNSCC) [83], refractory cHL [84], and metastatic ESCC [85]. Further, cemiplimab has been approved for metastatic cutaneous squamous cell carcinoma (CSCC) therapy [86].

Recently, study of the efficacy and safety of nivolumab in 440 patients with wild-type BRAF and mutant BRAF metastatic melanoma showed that nivolumab administration caused improved ORR regardless of the PD-L1 status of the tumor [87]. As well, the durable response rate (DRR) was 14.8 months for wild-type BRAF and 11.2 months for mutant BRAF. Accordingly, it was speculated that nivolumab has comparable efficacy and safety consequences in patients with wild-type or mutant BRAF [87]. Likewise, pembrolizumab showed great potential for the treatment of advanced melanoma regardless of BRAF V600E/K mutation status [88]. Besides, a metaanalysis investigating the efficacy and safety of nivolumab for advanced NSCLC patients evidenced the strong capacity of administration of nivolumab $(3 \mathrm{mg} / \mathrm{kg}$ ), as demonstrated with ameliorated ORR, OS, and also PFS [89]. Moreover, patients with positive PD-L1 expression showed a more favorable response to nivolumab [89]. Moreover, nivolumab could also elicit long-term clinical merits and a favorable tolerability profile than docetaxel, a taxoid antineoplastic agent, in patients with advanced NSCLC [90]. Meanwhile, OS rates with nivolumab versus docetaxel were $23 \%$ versus $8 \%$ in squamous NSCLC and $29 \%$ versus $16 \%$ in nonsquamous NSCLC [90]. Also, combination therapy with pembrolizumab and radiotherapy (RT) could support improved PFS and OS compared with monotherapy with RT with an acceptable safety profile in NSCLC patients [91]. The median OS was 10.7 months versus 5.3 months in the pembrolizumab plus RT group versus RT alone. Thereby, it was simplified that application of ICIs along with RT may be considered as an effective strategy in patients with NSCLC or even other tumors [91]. Pembrolizumab could also improve OS in patients with locally advanced or metastatic urothelial carcinoma (UC), according to Sundahl et al. reports [92]. As well, results from another trial on $370 \mathrm{UC}$ patients revealed that pembrolizumab inspires acceptable DRR in cisplatin-ineligible patients (NCT02335424) [93]. This monoclonal antibody also elicited significant antitumor activity, as evidenced by improved ORR, with manageable toxicity in HNSCC [94]. Notwithstanding, administration of pembrolizumab was not able to affect OS and PFS in HNSCC patients compared with standard of care (SOC) chemotherapy regimens (cetuximab, docetaxel, or methotrexate) [94]. Moreover, pembrolizumab 
alone or in combination with platinum and 5-FU could be considered as first-line standards of care for HNSCC (NCT02358031) [95]. Besides, Chen and his colleagues showed that pembrolizumab could affect the ORR as well as complete response rate (CRR) in patients with cHL (NCT02453594) [96]. On the other hand, cemiplimab has shown substantial antitumor functions with a manageable safety profile in patients with metastatic CSCC $[97,98]$. The most common adverse events regardless of attribution during or after treatment of CSCC patients with cemiplimab $(3 \mathrm{mg} / \mathrm{kg})$ are fatigue $(27.0 \%)$ and diarrhea (23.5\%) [99]. As well, it was suggested that cemiplimab was correlated with benefits in OS and PFS in CSCC patients versus EGFR inhibitors and pembrolizumab, signifying its great potential in treating CSCC patients [100]. Cemiplimab monotherapy also could bring about higher OS and PFS than chemotherapy with platinumbased compounds in patients with advanced NSCLC, and so suggesting a potential new therapeutic approach for this patient population [101].

\section{PD-L1 inhibitors}

Three anti-PD-L1 antibodies have gained approval from the FDA: atezolizumab (IgG4 mAb), and also durvalumab and avelumab, which are IgG1 mAb [102]. Since 2016, atezolizumab as the first FDA-approved PD-LI inhibitor has been approved for advanced or metastatic UC patients [103]. Also, it has been indicated for metastatic NSCLC patients whose malignancy progressed throughout or upon platinum-based compound therapy [104]. Moreover, atezolizumab plus angiogenesis inhibitor bevacizumab is used for metastatic HCC patients therapy [105], and also in combination with mitogen-activated extracellular kinase (MEK) inhibitor cobimetinib and B-Raf enzyme inhibitor vemurafenib is applied for the treatment of patients with metastatic melanoma [106]. Since 2017, durvalumab has been approved for the treatment of advanced or metastatic UC [107] as well as metastatic Merkel cell carcinoma (MCC)[108]. Durvalumab plus etoposide and either carboplatin or cisplatin are now used as a first-line treatment for advanced NSCLC therapy [109]. Since 2017, avelumab has been utilized for MCC [108] and metastatic UC therapy [110]. Moreover, since 2019, avelumab plus tyrosine kinase inhibitor axitinib is used as the first-line treatment of patients with advanced RCC [111].

Currently, a phase 3 trial indicated that atezolizumab could stimulate objective responses in metastatic UC with or without platinum-based chemotherapy, as shown by improved PFS and also acceptable safety profile [112]. Also, atezolizumab in patients with previously treated advanced NSCLC exhibited significant amelioration in OS versus docetaxel (13.3 versus 9.8 months) without unexpected toxicities [113]. As well, this ICI plus carboplatin and paclitaxel showed superiority over chemotherapy alone in terms of improved OS and PFS in advanced NSCLC patients according to West et al. reports [114]. Gutzmer et al. also found that combination therapy with atezolizumab plus targeted therapy with vemurafenib and cobimetinib was safe and tolerable and considerably promoted PFS in patients with BRAFV600 mutation-positive advanced melanoma [106]. Nonetheless, some adverse events such as increased blood creatinine phosphokinase, lipase and alanine aminotransferase, diarrhea, rash, arthralgia, pyrexia were shown [106]. Another PD-L1 inhibitor, durvalumab, has demonstrated clinical benefit in patients with locally advanced or metastatic UC. Durvalumab administration $(10 \mathrm{mg} / \mathrm{kg})$ could provoke improved ORR, OS, and PFS concomitant with the excellent safety profile in patients with UC (NCT01693562) [115]. Besides, durvalumab plus platinum-etoposide supported improved OS versus platinum-etoposide therapy (13.0 months versus 10.3 months) in patients with SCLC without any significant difference respecting grade 3 or 4 adverse events percentages between two groups [109]. As well, this PD-L1 inhibitor resulted in improved OS and PFS along with DOR more obviously patients with PD-L1 expressing tumors [116]. Apart from efficacy, another trial evaluating long-term safety supported that avelumab administration had no new or unexpected adverse events and no treatment-related deaths in MCC patients during 3 years follow-up [117]. This evidence reflects the capacities of avelumab as a SOC treatment option for MCC [117]. Avelumab also in combination with axitinib is now described as first-line treatment for patients with advanced RCC with manageable safety profile and substantial tolerability $[111,118]$. In advanced RCC, addition of the avelumab to axitinib also improved PFS compared with sunitinib, an FDA-approved VEGFR inhibitor for RCC patients [119].

\section{Corresponding mechanism complicated in tumor resistance to ICls}

It is now generally documented that tumor cells make close interfaces with the ECM, stromal cells, and also immune cells which typically exist in TME. Such cells in TME support evolving chronic inflammation, enhancing immunomodulation, and simultaneously providing a pro-angiogenic intratumoral microenvironment, and thus ease tumor cells escape from recognition and subsequent removal by host immunosurveillance $[120,121]$. For eradication of malignant cells, $T$ cells are required to be efficiently induced by dendritic cells (DCs) in peripheral lymph nodes, home to the malignant tissue, extravasate from malignant tissue blood vessels, and finally infiltrate barricades (such as stromal tissue) to encounter 
cancer cells [122, 123]. Developing tumors mainly barricade these necessities for $\mathrm{T}$ cell immunosurveillance for preventing immune cell-elicited tumor eradication. Given that the efficacy of ICIs treatment is principally inspired by $\mathrm{T}$ cells, such competent immune escape may ultimately bring about failures in ICIs therapy. A promotion in PD-L1 in the TME by malignant cells and also APCs is thought to be the most communal approach by which malignant cells bypass immune surveillance [124, 125]. The tryptophan catabolism inside the TME also is contributed to the negative regulation of anti-tumor immune responses. In TME, tryptophan catabolism induced by the IDO, which is largely expressed by myeloid-derived suppressor cells (MDSC) and tumor cells, results in making some immunosuppressive metabolites (e.g., kynurenine) [126]. Bothe kynurenine functions and also exhaustion of the vital amino acid tryptophan impede $\mathrm{T}$ cell's clonal expansion and may entice either $\mathrm{T}$ cell anergy or apoptosis [126]. Owing to this fact, the combined effects of IDO inhibitors and ICIs have been speculated as a rational plan to provoke TILs and their functional aptitudes in the TME. This intervention can facilitate removing both IDO-expressing and IDO-nonexpressing poorly immunogenic malignant cells [127]. Likewise, the existence of regulatory $\mathrm{T}$ cells (Treg cells), $\mathrm{T}$ helper 2 (TH2) cells, and MDSCs in TME is an additional impediment, compromising the efficacy of ICIs therapies by suppressing CTL- and T helper 1 (TH1) cell-mediated tumor immunosurveillance [128, 129]. Exhaustion of such cell types has experimentally been exposed to augment anti-tumor immune responses defeating resistance to ICI [21]. Besides, an intrinsic mechanism such as up-regulation of the tumor-inducing WNT- $\beta$-catenin signaling pathways may avert TILs and CD103+DC infiltration into the TME. As evidenced in melanoma, it appears that $\beta$-catenin activation could suppress the expression of chemokine chemokine $(\mathrm{C}-\mathrm{C}$ motif) ligands 4 (CCL4), which is mainly complicated in immune cell infiltration into TME [130, 131]. Besides, loss of phosphatase and tensin homolog (PTEN) is allied with improved levels of CCL2 and vascular endothelial growth factor (VEGF), reduced infiltration of $\mathrm{T}$ cells, and finally resistance to PD-1 inhibitors [132]. Thereby, stimulating DCs migration, maturation, and activation by blockade of immunosuppressive factors, such as VEGF, IL-10, and TGF- $\beta$ efficiently enables sufficient T-cell priming and cooperation with ICI. As well, cyclooxygenase (COX) expression by tumor cells can hinder tumor cell immunosurveillance as a result of up reregulation of the prostaglandin E2 (PGE2) expression, preparing an inflammatory environment for tumor growth [133, 134]. Moreover, COX-2 overexpression mainly improves Treg trafficking into TME. The metabolic interaction between the transformed cells and immune cells also may give rise to the poor response to treatment with ICI, as evidenced by the study of the tumor and immune cell glucose and glutamine metabolism [135]. In fact, glucose and glutamine metabolism up-regulate the PD-L1 expression in transformed cells by the positive regulation of epidermal growth factor receptor (EGFR)/ extracellular signalregulated kinase (ERK)/C-Jun pathway [135]. Hence, inhibiting tumor glucose or glutamine metabolism by therapeutic molecules in combination with PD-1/PD-L1 blockade therapies may defeat tumor cell resistance to ICIs. On the other hand, janus kinase (JAK) 1/2 loss-offunction mutations are other tools exploited by tumor cells to trigger primary resistance to PD-1 inhibitors by down-regulation of PD-1 expression [136].

\section{Combination therapy using ICls}

The FDA approved atezolizumab and durvalumab for use in combination with chemotherapy for first-line treatment of patients with advanced SCLC. These approvals were rendering consequences derived from two randomized controlled trials, IMpower133 (atezolizumab) [137] and CASPIAN (durvalumab) [109]. These trials revealed increases in OS with anti-PD-L1 antibodies when used in combination with platinum-based chemotherapy as compared with chemotherapy alone [138]. Atezolizumab has also been approved as a first-line NSCLC irrespective of PD-L1 expression in combination with chemotherapy and bevacizumab [139].

\section{ICls with chemotherapy}

Recent studies have shown that the combined use of cyclophosphamide, ICI, and vinorelbine could stimulate APC recruitment and also activation, and so hurdle local and metastatic TNBC growth mainly by T-cellmediated influences in vivo [140]. The intervention, in fact, resulted in activating APCs, increasing intratumoral CD8 + T cells, and also promotion of the progenitor exhausted CD8 $+\mathrm{T}$ cells [140]. Also, anti-PD-1 and anti-PD-L1 inhibitors showed synergistic anti-tumor effects with vinorelbine, cyclophosphamide, and fluorouracil (5-FU) in vivo [141]. A study in mice models of breast cancer $(\mathrm{BC})$ and $\mathrm{B}$-cell lymphoma $(\mathrm{BCL})$ revealed that cyclophosphamide heightened circulating MDSC, whereas vinorelbine, cyclophosphamide, and also 5-FU diminished circulating APCs [141]. Vinorelbine and cyclophosphamide, but not 5-FU, also decreased circulating Tregs. However, it was found these events were in association with the administrated dosage of chemotherapeutic agents. For instance, cyclophosphamide (at low doses) and 5-FU (at medium doses) marginally improved circulating Tregs. Further, vinorelbine abridged circulating NKs, whereas low doses of cyclophosphamide and 
5-FU improved circulating NKs. These results evidenced the preclinical synergy between chemotherapeutics and anti-PD-L1 [141]. Moreover, monotherapy with CTLA-4 inhibitor and also combination therapy with CTLA-4 inhibitor and either cyclophosphamide or gemcitabine proved their therapeutic effect in $\mathrm{BC}$ and also CRC mice model [142]. Notwithstanding, some tumor-bearing mice advanced spontaneous metastases under continuous

Table $1 \mathrm{ICl}$ combination therapy with chemotherapy in preclinical models

\begin{tabular}{|c|c|c|c|c|}
\hline Tumor & Target IC & Agent (s) & Result (s) & References \\
\hline Triple-negative breast cancer & PD-1 & Cyclophosphamide & $\begin{array}{l}\text { Induction of the synergistic effect with } \mathrm{ICl} \text { through } \\
\text { induction of the antigen-presenting cells along with } \\
\text { promoting intratumoral CD8 }+\mathrm{T} \text { cells }\end{array}$ & [140] \\
\hline $\begin{array}{l}\text { B-cell lymphoma } \\
\text { Breast cancer }\end{array}$ & $\begin{array}{l}\text { PD-1 } \\
\text { PD-L1 }\end{array}$ & $\begin{array}{l}\text { Vinorelbine } \\
\text { Cyclophosphamide Fluorouracil }\end{array}$ & Induction of the synergistic effect & [141] \\
\hline Breast cancer & CTLA-4 & $\begin{array}{l}\text { Gemcitabine } \\
\text { Cyclophosphamide }\end{array}$ & $\begin{array}{l}\text { Stimulation of tumor regression, while some cases } \\
\text { showed the development of spontaneous metastases }\end{array}$ & [142] \\
\hline $\begin{array}{l}\text { Colon cancer } \\
\text { Bladder cancer }\end{array}$ & $\begin{array}{l}\text { PD-1 } \\
\text { PD-L1 }\end{array}$ & $\begin{array}{l}\text { Methotrexate } \\
\text { Vinblastine } \\
\text { Doxorubicin } \\
\text { Cis-platin } \\
\text { Cyclophosphamide }\end{array}$ & Substantial robust anti-tumor response in vivo & [248] \\
\hline Gastrointestinal cancer & PD-L1 & Gemcitabine & $\begin{array}{l}\text { Tumor growth inhibition, reducing MDSCs and M2 } \\
\text { macrophages, and improved OS }\end{array}$ & [144] \\
\hline Pancreatic ductal adenocarcinoma & PD-1 & Gemcitabine & $\begin{array}{l}\text { Inspiring the infiltration of Th1 lymphocytes and M1 } \\
\text { macrophages along with extended OS }\end{array}$ & [249] \\
\hline Small-cell lung carcinoma & $\begin{array}{l}\text { PD-1 } \\
\text { PD-L1 }\end{array}$ & Gemcitabine & $\begin{array}{l}\text { Improving the antitumorigenic CD } 8+\text { cytotoxic T cells, } \\
\text { DCs, and M1 macrophage populations concurrently } \\
\text { decrease in M } 2 \text { macrophage and MDSCs, and finally } \\
\text { enhancement in the expression of the type I interferon } \\
\text { beta } 1 \text { gene, IFN } \beta \text {, and chemokines, CCL } 5 \text { and CXCL10 }\end{array}$ & [145] \\
\hline Lewis lung carcinoma & PD-1 & Gemcitabine & $\begin{array}{l}\text { Robust anti-tumor impacts along with suppression of } \\
\text { recurrence of LLC by rises in CD8 }+ \text { and CD4 + T cells } \\
\text { proportion }\end{array}$ & [146] \\
\hline Mesothelioma & PD-1 & Gemcitabine & Tumor regression and improved OS rate & [147] \\
\hline Lewis lung carcinoma & PD-1 & Oxaliplatin & Tumor regression by activation of APCs and TILs & [150] \\
\hline Colon cancer & $\begin{array}{l}\text { PD-1 } \\
\text { PD-L1 }\end{array}$ & $\begin{array}{l}\text { Cisplatin } \\
\text { Oxaliplatin }\end{array}$ & $\begin{array}{l}\text { Promotion of the expression of T cell-attracting } \\
\text { chemokines (CXCL9, CXCL 10, and CCL5), and } \\
\text { Provoking T cell activation and recruitment into TME }\end{array}$ & [151] \\
\hline Triple-negative breast cancer & PD-1 & Paclitaxel & $\begin{array}{l}\text { Instigation of a synergistic effect with } \mathrm{ICl} \text { through trans- } \\
\text { forming the tumor immune microenvironment }\end{array}$ & [154] \\
\hline Triple-negative breast cancer & PD-L1 & Paclitaxel & $\begin{array}{l}\text { Stimulating tumor regression, metastasis inhibition, } \\
\text { and recurrence preventive }\end{array}$ & [155] \\
\hline $\begin{array}{l}\text { Colon cancer } \\
\text { Cervical cancer } \\
\text { Lung cancer } \\
\text { Melanoma }\end{array}$ & PD-L1 & Paclitaxel & $\begin{array}{l}\text { Enhancing the infiltration and function of T cells and } \\
\text { DCs within tumors }\end{array}$ & [156] \\
\hline $\begin{array}{l}\text { Colon cancer } \\
\text { Bladder cancer }\end{array}$ & $\begin{array}{l}\text { PD-1 } \\
\text { PD-L1 }\end{array}$ & Doxorubicin & $\begin{array}{l}\text { Showing the anti-tumor impact of the combination of } \\
\text { immunotherapy in the MC } 38 \text { colon and MB49 bladder } \\
\text { models, a lack of response in the 4T1 breast model, } \\
\text { and suppression of ICls potential in the MBT-2 bladder } \\
\text { model }\end{array}$ & [248] \\
\hline B cell lymphoma & PD-1 & Doxorubicin & $\begin{array}{l}\text { Verification of the therapeutic capacity of doxorubicin- } \\
\text { loaded microbubbles (RDMs) with ICl }\end{array}$ & [250] \\
\hline Ovarian cancer & PD-L1 & Cisplatin & Prolonged OS of treated mice & [251] \\
\hline Lung cancer & PD-L1 & Cisplatin & Reducing tumor growth & [152] \\
\hline B cell lymphoma & PD-1 & Doxorubicin & $\begin{array}{l}\text { Showing synergistic effects with ICI by up-regulation } \\
\text { of IFN- } \gamma\end{array}$ & [252] \\
\hline Fibrosarcoma & PD-1 & Methotrexate & Notable anti-tumor effect in vivo & [253] \\
\hline
\end{tabular}

ICl immune checkpoint inhibitor, $P D-1$ programmed cell death protein 1, PD-L1 programmed death-ligand 1, CTLA-4 cytotoxic-T-lymphocyte-associated protein 4, IFN interferon, Tregs regulatory T cells, TME tumor microenvironment, TLL tumor-infiltrating lymphocytes, APC antigen-presenting cell, MDSC myeloid-derived suppressor cells, OS overall survival 
treatment with combined regimen [142]. Moreover, a phase 1 clinical trial in 15 patients with refractory and metastatic HNSCC indicated that combination therapy with PD-1 inhibitor cemiplimab plus cyclophosphamide, radiation therapy (RT), and granulocyte-macrophage colony-stimulating factor (GM-CSF) could demonstrate acceptable safety profile [143]. However, the regimen resulted in no significant effects compared to the monotherapy with cemiplimab.

Besides, gemcitabine combined with anti- PD-L1 antibody inhibited tumor growth in advanced pancreatic ductal adenocarcinoma (PDAC) murine models [144]. The combined application of PD-L1 inhibitor and gemcitabine improved median OS of treated mice compared to the monotherapy with ICI. Moreover, combination therapy brought about reduced circulating splenic and intratumoral MDSCs, and also M2 macrophages. In contrast, tumor samples from mice administrated with ICI plus gemcitabine had augmented numbers of infiltrating cytotoxic T-cells [144]. Furthermore, addition of the PD-L1 inhibitor to gemcitabine elicited an antitumor response in SCLC mice models by a reduction in M2 macrophage and MDSCs concurrently an enhancement in the expression of the type I interferon beta 1 gene (IFN $\beta$ ), and CCL5 and CXCL10, largely contributing to the induction of TILs recruitment into tumor tissues $[145,146]$. On the other hand, the combination of gemcitabine and PD-1 inhibitors reduced tumor growth and also improved OS in mesothelioma murine model [147]. Combination therapy also improved ORR in two patients with mesothelioma, who were resistant to gemcitabine or PD-1 inhibitor as monotherapy [147]. Likewise, evaluation of the safety and tolerability of the nivolumab as monotherapy or plus gemcitabine and cisplatin as combination therapy in Japanese patients with biliary tract cancer (BTC) was conducted during an open-label, phase

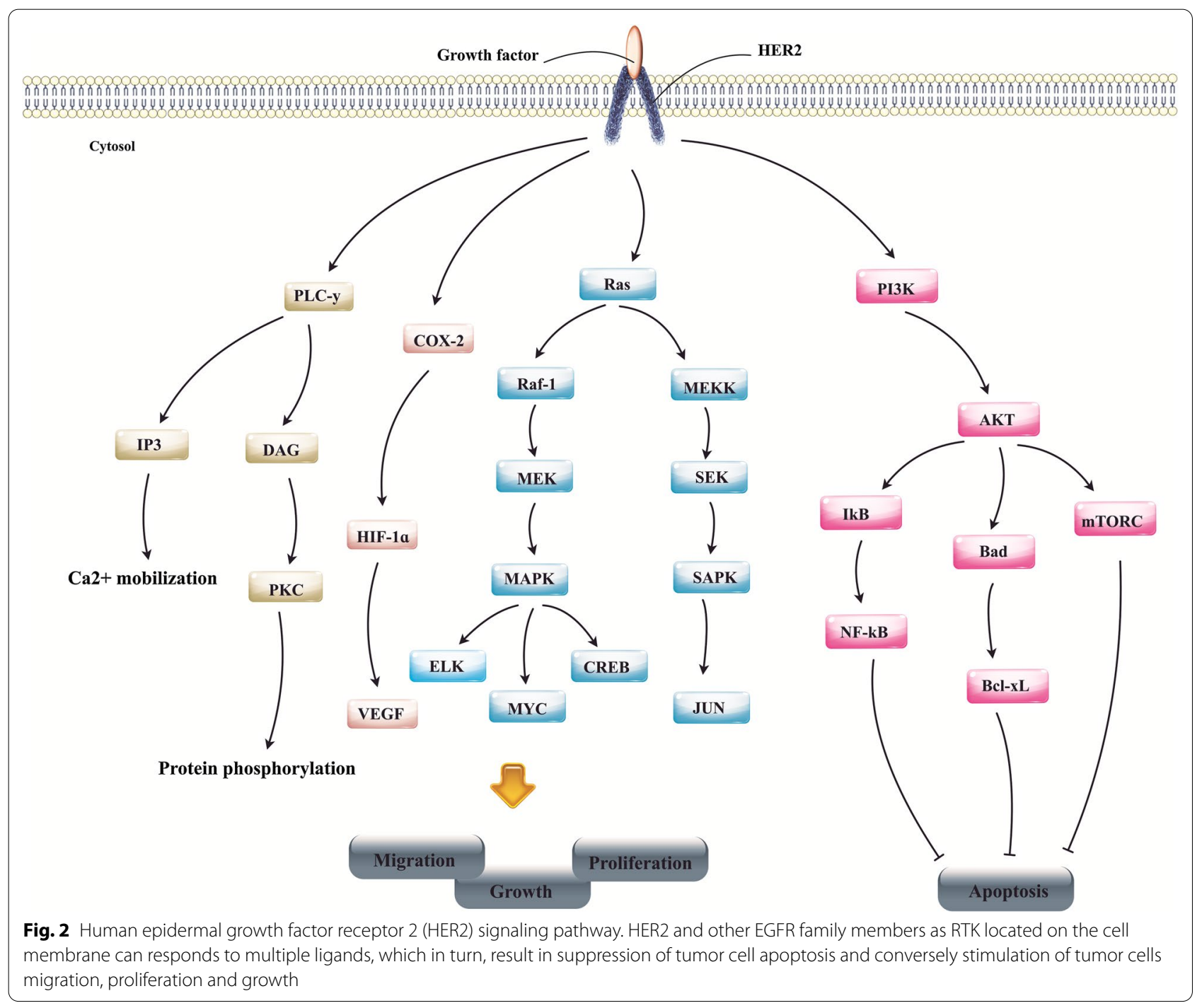


1 clinical trial [148]. Meanwhile, combination therapy exhibited superiority over monotherapy in terms of the improved OS (15.4 versus 5.2 months), enhanced median PFS (4.2 versus 1.4 months), and also achieved ORR (11 patients versus 1 patient) [148]. Likewise, combined use of nivolumab plus gemcitabine and cisplatin induced favorable effects in BTC patients concomitant with some grade 3 or higher adverse events such as thrombocytopenia (56\%) and neutropenia (22\%) [149]. Importnatly, analysis showed that fitness might be a biomarker for predicting clinical response and also Fas ligand (FasL), monocyte chemoattractant protein-1 (MCP-1/CCL2), and IFN- $\gamma$ serum levels were associated with prognosis [149]. Other reports also have shown that oxaliplatin as another chemotherapeutic agent could induce robust immunogenic cell death (ICD) in Lewis lung carcinoma (LLC) cells and simultaneously improve DCs and also CTL in LLC tumor tissues, leading to the tumor regression in vivo [150]. Also, combined use of oxaliplatin and PD-L1 inhibitor showed a higher anti-tumor response than monotherapy with oxaliplatin in murine lung carcinoma [150]. It seems that promoted numbers of CTLs in tumor tissue, as evidenced in previous study, rely on the improved expression of $\mathrm{T}$ cell-attracting chemokines (CXCL9, CXCL10, and CCL5) as shown in colon cancer MC38 cell bearing mice upon oxaliplatin treatment [151]. Moreover, cisplatin treatment may synergize with PD-1/ PD-L1 inhibitors to ameliorate the clinical response, which is principally caused by improved PD-L1 expression [152].

Recently, Chen and coworkers suggested that doxorubicin and cisplatin might stimulate a more valued TME and boost the likelihood of response to anti-PD-1 antibody in TNBC [153]. Furthermore, metronomic paclitaxel could enhance the therapeutic merits of PD-1 in TNBC by altering the tumor immune microenvironment, offering robust proof for the application of this intervention in TNBC patients [154]. Also, paclitaxel improved the efficacy of PD-L1 blockade therapy in tumor animal models and demonstrated a synergistic impact on tumor eradication, metastasis suppression, and also recurrence prevention [155]. Such events might arise from reduced recruitment of Treg cells into TME induced by paclitaxel [155]. In another study, low dose of nanomicelle-encapsulated paclitaxel (nano- paclitaxel) treatment stimulated tumor regression by improving the infiltration and activation of TILs and DCs within tumors [156]. Coadministration of a low dose of nano- paclitaxel and PD-1 inhibitor also provoked CD8 $+\mathrm{T}$ cell-dependent antitumor immunity and markedly enhanced the therapeutic efficacy in murine colon cancer CT26 cells and MC38 cell bearing mice [156]. As well, the synergistic effects of PD-1 inhibitor and nanoparticle albumin-bound (nab)-paclitaxel have been recently validated in Chinese patients with refractory melanoma [157]. Accordingly, $\mathrm{Li}$ et al. indicated that combination therapy gave rise to the improved ORR and PFS than the control group. Although most patients exhibited adverse events, only $17.2 \%$ of participants experienced grade 3 severe adverse events, such as neutropenia (18.8\%) [157]. In addition, PD-1/PD-L1 inhibitor plus nab-paclitaxel supported meaningfully longer OS and higher response than ICI monotherapy in patients suffering from the metastatic NSCLC [158]. As well, another clinical trial evidenced the safety and efficacy of doxorubicin chemotherapy plus pembrolizumab in 23 patients with soft tissue sarcomas (STS) [159]. The regimen induced objective response significantly and also prolonged PFS more evidently than monotherapy with pembrolizumab [159].

A summary of conducted studies respecting combination therapy with ICIs and chemotherapy have been listed in (Tables 1 and 4).

\section{ICls with HER2-targeted therapies}

Human epidermal growth factor receptor (HER) 2 amplification befalls numerous tumor types counting breast, gastric, salivary, vaginal, bladder, CRC endometrial, and cervical. HER2 activation results in the activation of a myriad of oncogenic signaling axes (e.g., PI3K/ $\mathrm{AKT}$ and Ras/Raf/ERK), thereby improving malignant cell survival, proliferation, migration, and also resistance to immunotherapy (Fig. 2) [160]. Thereby, it is determined as an emerging therapeutic target for breast cancer, and so diversity of ingredients comprising trastuzumab, pertuzumab, lapatinib, neratinib, and trastuzumab emtansine (T-DM1) have been gained approval from the FDA for the treatment of HER2expressing breast cancer [35]. Notably, HER2-targeted therapy likewise was shown to ameliorate outcomes in HER2-expressing gastric cancer [35].

Recent reports have shown that trastuzumab deruxtecan (DS-8201a), a HER2-targeting antibody, could promote antitumor immunity by enhanced expression of DCs markers, boosted expression of MHC class I in tumor cells, and also the rejection of rechallenged murine HER2-expressing breast cancer cells by adaptive immune cells [161]. Besides, DS-8201a showed a synergistic effect with an anti-PD-1 antibody likely supported by enhanced T-cell mediated anti-tumor activities and upregulated PD-L1 expression [161]. Likewise, combination therapy with DS-8201a and anti-CTLA-4 antibody persuaded more prominent antitumor effects compared with monotherapy with each agent in murine HER2-expressing breast cancer cells mainly by enhanced tumor-infiltrating $\mathrm{CD} 4+$ and $\mathrm{CD} 8+\mathrm{T}$ cells in vivo [162]. Co-administration of T-DM1 with anti-CTLA-4/PD-1 also attenuated 


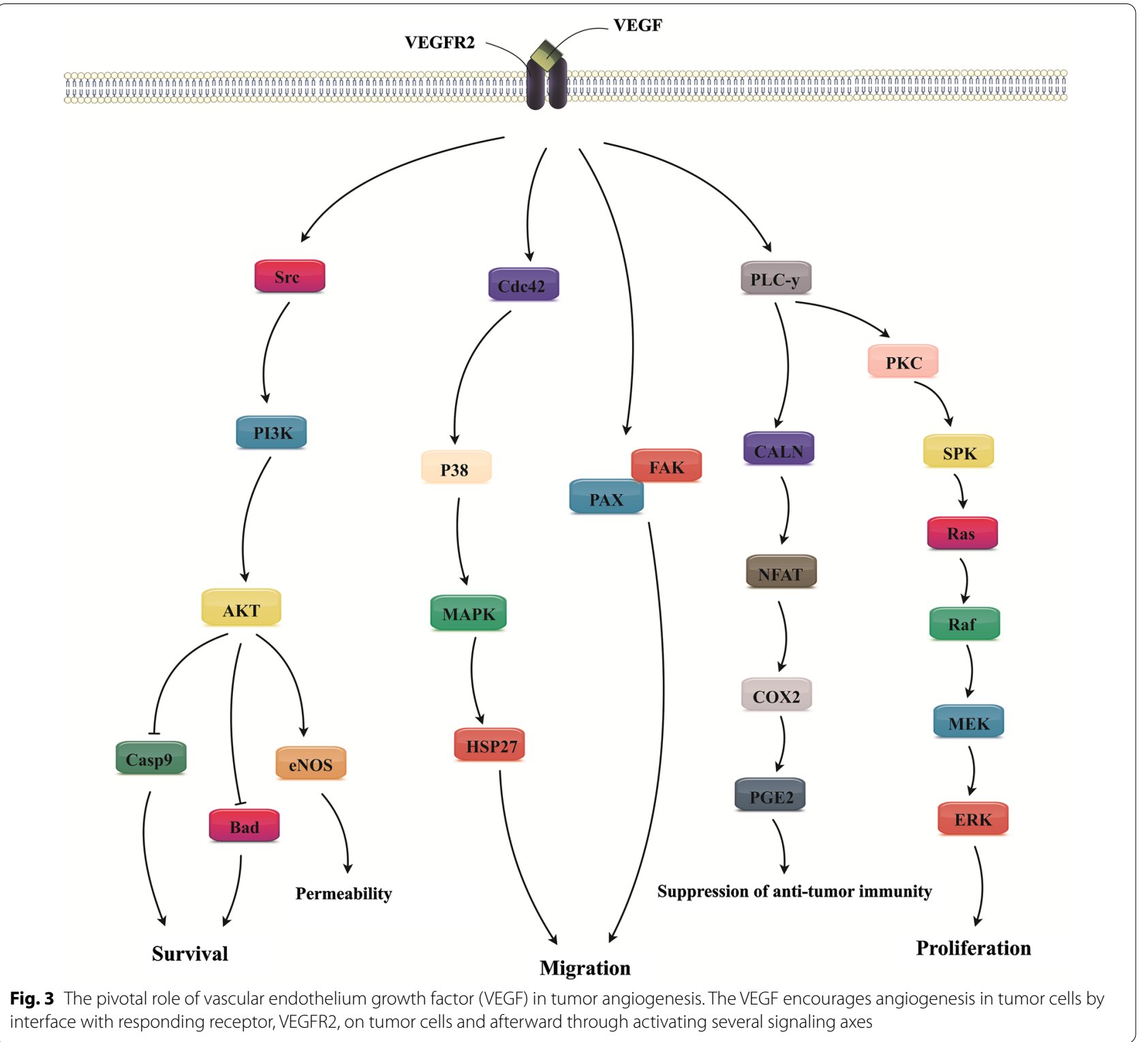

tumor cell resistance to ICIs in a HER2-expressing orthotopic breast cancer model. This event was likely related to the improved recruitment of TILs concomitant with enhanced Th1 cell polarization [163]. Recently, D'Amico and colleagues evaluated therapeutic merits and immune-mediated mechanisms of a novel HER2-targeting antibody-drug conjugates (ADCs) bearing a potent anthracycline derivate as payload (T-PNU) in a human HER2-expressing breast cancer model [164]. They found that co-treatment of animals with T-PNU together with anti-PD1 anti-body robustly potentiated tumor regression by increasing CTLs activities [164]. In addition, the study of safety and efficacy of pembrolizumab in combination with trastuzumab and chemotherapy in first-line
HER2-expressing metastatic oesophagogastric cancer was conducted between Nov 11, 2016, and Jan 23, 2019, in 37 patients during a phase 2 trial [129]. Achieved results exposed that pembrolizumab could be safely combined with trastuzumab and platinum-based drugs and also had significant activity in HER2-expressing metastatic oesophagogastric cancer [129]. Also, margetuximab, a novel anti-HER2 monoclonal antibody showed acceptable safety, tolerability, and also significant efficacy upon combination therapy with pembrolizumab in 92 patients with HER2-positive gastro-oesophageal adenocarcinoma [165]. Severe treatment-related adverse events were exhibited in 9 of $92(9 \%)$ patients, with no treatment-related deaths. In terms of the efficacy, objective 
responses were shown in 17 of 92 (18.48\%) patients [165]. Ultimately, nivolumab and trastuzumab in combination improved PFS with the manageable safety profile in gastric cancer patients, as reported by Tian et al. [166].

\section{ICls with anti-angiogenic agents}

Abnormal vasculature is one the most prominent possessions of solid tumors and is complicated in tumor immune escape [167]. This deregulation results from the improvement in the expression of pro-angiogenic factors mainly affecting immune cells both migration and activation [167]. Indeed, anti-angiogenic therapy recently has been developed to fight cancer by abolishing the nutrient and oxygen supply to the tumor cells by a reduction in vascular network and averting the generation of new blood vessels. Given the central role of VEGF signaling in angiogenesis (Fig. 3), the approved angiogenesis inhibitors for tumor therapy chiefly depend on the targeting VEGF actions. Apart from modification of angiogenesis, such drugs can augment immune therapy as a result of the immunomodulatory activities of VEGF [168]. Correspondingly, angiogenesis inhibitors ease alteration of the TME from immunosuppressive to immune-supportive by intensifying the recruitment and induction of immune cells activities. To date, axitinib, bevacizumab, cabozantinib, everolimus, lenalidomide, lenvatinib mesylate, pazopanib, ramucirumab, regorafenib, sorafenib, sunitinib, thalidomide, vandetanib and also Ziv-aflibercept have gained approval from FDA as efficient angiogenesis inhibitors [169]. Bevacizumab as the first FDA-approved VEGF-targeted agent has been indicated for the treatment of a myriad of human tumors, such as CRC, NSCLC, RCC, breast cancer, ovarian cancer, and cervical cancer alone or in combination with other therapeutics [170]. Atezolizumab plus bevacizumab, paclitaxel, and carboplatin have been applied as the first-line treatment of NSCLC patients [171]. Furthermore, bevacizumab plus atezolizumab demonstrated synergistic impact on median OS of RCC patients [172], and also in combination with nivolumab established modest efficacy in ovarian cancer patients [173]. Besides, the safety and also efficacy (improved ORR) of co-administration of PD-L1 inhibitor avelumab with angiogenesis inhibitor axitinib has been evidenced in HCC [174] and also RCC [32] patients during a phase $1 \mathrm{~b}$ study. Also, co-administration of axitinib plus pembrolizumab caused improved median PFS in patients with sarcoma [168], while combined use of regorafenib plus nivolumab showed a manageable safety profile and also favorable antitumor effects in patients with gastric and CRC [175]. Objective tumor response was detected in $40 \%$, containing gastric cancer (44\%) and CRC (36\%). Also, median PFS was 5.6 in gastric cancer patients and 7.9 months in patients with and
CRC [175]. In contrast, a study in 23 patients with metastatic CRC signified that regorafenib plus nivolumab had no objective response, proposing its non-significant clinical benefits in these patients [176]. Likewise, VEGFR2 inhibitor ramucirumab plus pembrolizumab showed restricted clinical positive effects with infrequent highgrade unwanted effects in patients with advanced BTC [34]. Besides, combined use of ICI and angiogenesis inhibitor lenvatinib supported promoted median OS, but not PFS, than lenvatinib alone in advanced-stage HCC patients [177]. As well, there is clear evidence presenting that addition of the nivolumab to sunitinib or pazopanib could be an effective alternative for the treatment of advanced RCC patients [34, 178].

\section{ICls with cancer vaccines (e.g., oncolytic viruses)}

Therapeutic cancer vaccines simplify abrogation of tumor progress, eradication of minimal residual disease (MRD), and also inaugurating the durable antitumor memory and ducking untoward reactions [179, 180]. Still, BCG lives, sipuleucel-T (Provenge) and talimogene laherparepvec (T-VEC) are three eminent cancer vaccines authorized by FDA to respectively treat bladder cancer, prostate cancer, and melanoma [181]. T-VEC is the first oncolytic viral immunotherapy, which its direct intratumoral administration stimulates local and systemic immunologic reactions ensuring malignant cell lysis, tracked by secretion of tumor-derived antigens and succeeding induction of tumor-specific effector T-cells [182]. The sipuleucel$\mathrm{T}$ vaccine also was developed respecting the notion of APCs, and thus its administration enables the presentation of tumor-derived antigens in a form that $\mathrm{T}$ cells can recognize [183]. Finally, BCG also is a type of immunotherapy vaccine instigating the immune system to fight tumor cells (as shown in bladder cancer) [184].

Various preliminary reports explain that combination therapy with ICIs and cancer vaccines may encourage reinforced immunogenicity and also fence immunosuppressive TME [30]. A recent report has exhibited that co-administration of cancer stem cell (CSC) lysate-pulsed dendritic cell (CSC-DC) with PD-L1 and CTLA-4 inhibitors considerably improved T cell proliferation, inhibited TGF- $\beta$ secretion, intensified IFN- $\gamma$ secretion, and finally improved host-specific CD $8+\mathrm{T}$ cell response versus CSCs in B16-F10 mice melanoma tumor model [185]. Similarly, combined use of GMCSF cell-based vaccines (GVAX) and CTLA-4 inhibitor decreased tumor size and restored the antitumor immune responses in melanoma [29], prostate [186], and also PDA [187] murine model. On the other hand, the DC tumor lysate-based vaccine together with antiPD-1 anti-body also brought about ameliorated OS in glioma [188] and also lung cancer [189] murine models. 
Table $2 \mathrm{ICl}$ combination therapy with OVs and other types of cancer vaccines

\begin{tabular}{|c|c|c|c|c|}
\hline Tumor & Target IC & Agent (s) & Result (s) & References \\
\hline Glioma & $\begin{array}{l}\text { CTLA-4 } \\
\text { PD-1 }\end{array}$ & IL-12-oHSV & $\begin{array}{l}\text { Induction M1 macrophage and T effector (CD4 + and CD8 + T cells) } \\
\text { function along with suppression of Treg }\end{array}$ & {$[198,254]$} \\
\hline Melanoma & $\begin{array}{l}\text { CTLA-4 } \\
\text { PD-1 }\end{array}$ & PLG & Promotion of CTL activity and inducing tumor regression & [255] \\
\hline $\begin{array}{l}\text { Rectal cancer } \\
\text { Osteosarcoma }\end{array}$ & PD-1 & hTERT-oAd & Hindrance of tumor regression by recruitment of CTLs & [256] \\
\hline Breast cancer & $\begin{array}{l}\text { PD-1 } \\
\text { CTLA-4 }\end{array}$ & sTGFßRIIFC-oAd & Abrogation of tumor development and lung and liver metastases & [257] \\
\hline HER-2 positive tumors & $\begin{array}{l}\text { PD-1 } \\
\text { PD-L1 }\end{array}$ & HER-2 B-cell peptide vaccine & Robust abrogation in tumor growth & [31] \\
\hline Melanoma & PD-L1 CTLA-4 & CSC-DC & $\begin{array}{l}\text { Enhancing T cell proliferation, suppressing TGF- } \beta \text { secretion, pro- } \\
\text { moting IFN- } \gamma \text { secretion, and finally triggering specific CD8 + T cell } \\
\text { response against CSCs }\end{array}$ & [185] \\
\hline $\begin{array}{l}\text { Lung cancer } \\
\text { Breast cancer } \\
\text { Melanoma } \\
\text { Lymphoma }\end{array}$ & $\begin{array}{l}\text { PD-1 } \\
\text { PD-L1 } \\
\text { CTLA-4 }\end{array}$ & GM-CSF-oHSV & Tumor regression and also stimulation of immunological memory & [257] \\
\hline Melanoma & PD-1 & T-VEC & $\begin{array}{l}\text { Hindrance of tumor growth by enhancing the infiltration of CTLS, } \\
\text { reducing intratumoral Tregs, and activation of Th1 in the TME }\end{array}$ & [258] \\
\hline Melanoma & $\begin{array}{l}\text { CTLA-4 } \\
\text { PD-1 }\end{array}$ & Ovalbumin & $\begin{array}{l}\text { Delay in tumor growth and extended OS rate of mice by increased } \\
\text { intratumoral CD8 + infiltration }\end{array}$ & [259] \\
\hline Glioma & PD-1 & ZIKV & Better OS rate of treated mice & [260] \\
\hline Rhabdomyosarcoma & PD-1 & oHSV & $\begin{array}{l}\text { Improving T effector (CD4 + and CD8 + T cells) function along with } \\
\text { suppression of Treg }\end{array}$ & [261] \\
\hline Melanoma & PD-L1 & oHSV & $\begin{array}{l}\text { Improving IFNy-producing CD8 + TILs activities, and promoted OS } \\
\text { rate }\end{array}$ & [262] \\
\hline Melanoma & PD-1 & Archaeosome-OVA & Robust tumor recession & [263] \\
\hline Glioma & PD-1 & EGFR-MV & $\begin{array}{l}\text { Recruitment and infiltration of TILs into the brains of treated mice, } \\
\text { and also improved OS rate }\end{array}$ & [197] \\
\hline Lung cancer & PD-1 & oAd & Reserve of tumor cell development mediated by activation of CTL & [196] \\
\hline Lung cancer & PD-L1 & Lm-LLO-E6 & Stimulation of prolonged OS rate & [264] \\
\hline Melanoma & $\begin{array}{l}\text { PD-1 } \\
\text { PD-L1 } \\
\text { CTLA-4 }\end{array}$ & CD40L- oAd & $\begin{array}{l}\text { Boosting the systemic level of tumor-specific CD8 }+T \text { cells, and } \\
\text { also augmentation of the ratio of intratumoral CD8 }+T \text { cells to Treg }\end{array}$ & [194] \\
\hline Glioma & PD-L1 & CD40L- oAd & Reserve of tumor growth accompanied with increased OS rate & [265] \\
\hline Prostate cancer & PD-1 & oAd & Stimulation of antigen-specific CD8 + T-cell responses & [266] \\
\hline Oral cancer & CTLA-4 & HPV E6/E7 peptide & $\begin{array}{l}\text { Promoted intratumoral levels of CD8 T cells concomitant with } \\
\text { reduced MDSCs and Treg }\end{array}$ & [267] \\
\hline Melanoma & PD-1 & Reovirus & Activation of and CTL along with abridged Treg activity & [268] \\
\hline Glioma & PD-1 & Reovirus & Promoting the expression of IFN-regulated gene expression & [269] \\
\hline Melanoma & PD-1 & oAd & Abrogated tumor growth accompanied with improved OS rate & [270] \\
\hline Melanoma & PD-1 & FlaB-Vax & $\begin{array}{l}\text { Significant rise in tumor-infiltrating effector memory CD8 }+ \text { T cells } \\
\text { and systemic IFNy levels }\end{array}$ & [192] \\
\hline Melanoma & $\begin{array}{l}\text { PD-1 } \\
\text { CTLA-4 }\end{array}$ & Ovalbumin & $\begin{array}{l}\text { Induction of CD8 +T cells activities associated with enhanced } \\
\text { eliminated tumor cells }\end{array}$ & [271] \\
\hline Melanoma & PD-L1 & MV & Stimulation of tumor regression & [272] \\
\hline Prostate cancer & PD-1 & VLP & Reduced tumor burden by activating CTLs & [273] \\
\hline
\end{tabular}

ICl immune checkpoint inhibitor, PD-1 programmed cell death protein 1, PD-L1 programmed death-ligand 1, CTLA-4 cytotoxic-T-lymphocyte-associated protein 4, CTLs cytotoxic T cells, IFN interferon, Tregs regulatory T cells, TME tumor microenvironment, TILs tumor-infiltrating lymphocytes, APC antigen-presenting cell, MDSC myeloid-derived suppressor cells, OS overall survival, TGF- $\beta$ transforming growth factor, DC dendritic cell, CSC cancer stem cell, oHSV oncolytic herpes simplex virus, oAd oncolytic adenovirus, MV measles virus, VSV Vesicular Stomatitis Virus, ZIKV Zika virus, FlaB-Vax Flagellin-adjuvanted tumor-specific peptide vaccination, HER2 human epidermal growth factor receptor 2, VLP virus-like particles, HPV human papillomavirus, EGFR epidermal growth factor receptor, $h T E R T$ human telomerase reverse transcriptase, TGF $\beta$ RIIFc transforming growth factor-beta receptor 2 fused with Fc protein, GM-CSF Granulocyte-macrophage colony-stimulating factor 
In another study, $\mathrm{Fu}$ et al. made an IFN $\gamma$-inducing cancer vaccine termed TEGVAX that combined GMCSF and multiple Toll-like receptor (TLR) agonists to raise the frequency of activated DCs [190]. TEGVAX induced tumor regression with stimulated systemic antitumor immunity. Though TEGVAX also surprisingly promoted PD-L1 expression in the TME, the combined use of nivolumab plus TEGVAX provoked complete regression of established tumors [190]. Also, adding the DNA vaccine against murine P815 mastocytoma to CTLA-4 and PD-1 blockade therapy led to the enhanced IFN- $\gamma$, IL12, and granzyme B generation in the TME and simultaneously suppressed liver metastasis and improved OS in treated mice [191]. Further, co-administration of TLR5 agonist flagellin-adjuvanted tumor-specific peptide vaccination (FlaB-Vax) with anti-PD-1 mAb inhibited melanoma tumor growth in B16-F10 cell bearing mice [192]. It was found that such desired effects were likely related to the activation of CD8 $+\mathrm{T}$ cells and APCs in tumor tissue and also enhanced systemic IFNY levels [192]. Recently, Yang and coworkers developed a novel vaccine nodule including a simple physical mixture of the peptide nanofibrous hydrogel, PD-1inhibitor, DCs, and tumor antigens [193]. The established vaccine supported a more prominent antitumor effect in tumor models comprising abrogated tumor development and prolonged animal OS as a result of triggering antitumor T-cell immunity [193]. As well, ICIs combination therapy with OVs was found to be able for inducing tumor regression through eliciting anti-tumor M1-like polarization, stimulating recruitment and functions of $\mathrm{T}$ effector cells, promoting IFN- $\gamma$ levels in TME, and ultimately down-regulation of Treg density and activity $[194,195]$. Meanwhile, it appears that local viral infection of tumors could circumvent systemic resistance to PD-1-immunotherapy by alteration the diversity of tumor-directed CD8 T-cells in CMT64 lung adenocarcinoma cells bearing murine [196]. Besides, direct measles virus [197] and oHSV expressing IL-12 [198] plus PD-1 and CTLA-4 blockade therapy stimulated tumor regression mainly by inducing the Th1, CTL cells, and M1-macrophages activation in the glioma murine model [194]. Owing to the fact that CD40 agonists make interactions with CD40 molecules on APCs and thereby potentiate their activation to prime tumor-specific CD8 + T cell responses, other studies have focused on CD40L role in inducing antitumor immunity [194]. Correspondingly, co-administration of adenovirus encoding a chimeric, membrane-bound CD40 ligand (ISF35) with PD-1 and CTLA-4 inhibitors caused complete removing of injected tumor cells in the melanoma murine model. Therapeutic effects were accompanied by enhancing the systemic level of tumor-specific $\mathrm{CD} 8+\mathrm{T}$ cells, and an augmented ratio of intratumoral CTLs to Tregs [194].

Current clinical trials also have signified that DCsbased mRNA vaccination in combination with ipilimumab could stimulate strong CD8 $+\mathrm{T}$-cell responses in stage III or IV melanoma patients [199]. As well, addition of the ipilimumab to GVAX in 30 patients with PDA also resulted in prolonged median overall survival (OS) [200]. In addition, nivolumab plus ISA 101, a synthetic longpeptide human papillomavirus (HPV) vaccine containing HPV-specific T cells, ameliorated median OS and ORR in patients with HPV-16-positive tumors [201].

A summary of conducted studies respecting combination therapy with ICIs and cancer vaccines have been listed in (Tables 2 and 4).

\section{ICls with radiation therapy (RT)}

Radiotherapy (RT) is employed generally as a standard treatment for more than $50 \%$ of patients suffering from tumors [202]. The abscopal influences elicited by local RT, which is defined as systemic anti-tumor immune reactions, enable the removing non-irradiated metastatic lesions at a distance farther from the primary area of irradiation [203]. As the ICIs can improve the systemic anti-tumor reactions of RT, combined use of RT and immunotherapy has recently attracted widespread attention [1]. The stimulation of immunogenic cancer cell death is the common mechanism for most RT plans. Then, the DCs are stimulated by the secreted danger signals and by taking up tumor peptides established by irradiated cells, and in turn, facilitates DCs-dependent $\mathrm{T}$ cells activation [1].

Studies have reported that RT in combination with targeting CTLA-4 and/or PD-1/PD-L1 could provoke CTLs-mediated anti-tumor immunity [28]. For instance, in glioma xenograft-bearing mice, combination therapy with PD-1 blockade and dose brain-directed radiation (10 Gy) resulted in anti-tumor impacts with a $75 \%$ complete pathologic response and also substantially improved OS mainly caused by activation of CTLs and macrophages [204]. Meanwhile, RT seemed to stimulate macrophage repolarization, enhancing $\mathrm{M} 1 / \mathrm{M} 2$ ratio [204]. However, other reports revealed that RT combined with anti-PD-1 treatment might lead to more severe lung injury in the tumor cell-bearing mice, attended by boosted neutrophil infiltration and enhanced inflammatory response [205]. Thereby, tight consideration must be taken during this combination therapy to ameliorate the safety profile. Further, LM8 osteosarcoma cells bearing mice irradiated with either carbon ions or $\mathrm{x}$-rays along with PD-1 and CTLA-4 inhibitors experienced abrogated growth of the abscopal tumors, which was mediated by 
increased CD8 + cells unlike mice treated with RT or ICI alone [206]. The achieved results indicated that adding high-energy carbon ion radiation therapy to ICI can be considered as an efficient plan for the treatment of advanced tumors [206]. RT (20 Gy) plus PD-1 or PD-L1 blocked therapy also robustly potentiated OS rate in castration-resistant prostate cancer (CRPC) preclinical model than monotherapy with each agent [207]. Meanwhile, the median OS for anti-PD-L1 monotherapy was 13 days versus 30 days for anti-PD-L1 plus RT, and antiPD-1 monotherapy was 21 days versus 36 days for antiPD-1 plus RT [207].

In this regard, a trial conducted, between February 2016 and December 2017, on 124 patients with advanced NSCLC verified the safety and efficacy of combination therapy with nivolumab and RT [208]. Results revealed that previous RT could be an independent prognostic marker of promising prognosis after nivolumab therapy and also could improve the ORR to nivolumab treatment [208]. In this trial, ORR was enhanced from $19 \%$ (RT group) and 28\% (nivolumab group) to $36.4 \%$ (RT plus nivolumab group) [208]. Likewise, patients (e.g., NSCLC and HNSCC) treated with PD-1/PD-L1 blocked therapy could benefit from local RT, as evidenced by longer PFS and OS [209]. Similarly, the combination of ICI and RT supported enhanced OS, PFS, and disease control rate (DCR) in patients with NSCLC and lung cancer [210]. The addition of the hypofractionated body radiotherapy (H-RT) to nivolumab or ipilimumab also was found that be safe and also served therapeutic merits in melanoma and RCC patients [211]. Other trials also have verified the safety of RT plus ICI in tumor patients with manageable ir-AEs [212, 213]. Nonetheless, Pike et al. have found that extracranial or prolonged regimen of RT might augment the risk of severe lymphopenia, accompanied by poorer survival in patients treated with ICI [214].

\section{ICls with ACT}

Adoptive cell therapy (ACT) with using TILs or genemodified $\mathrm{T}$ cells expressing novel $\mathrm{T}$ cell receptors (TCR) or chimeric antigen receptors (CAR) is another tactic to inspire the immune system to induce and so detect maligned cells and eradicate them $[215,216]$. Responders to ICI therapy usually suffer from T cell-inflamed tumors, reflecting the significance of evolving approaches that adapt non-T cell-inflamed tumors to $\mathrm{T}$ cell-inflamed tumors. There is some report indicating that co-administration of anti-PD-L1 antibody plus TILs might enhance

Table $3 \mathrm{ICl}$ combination therapy with CXCR4 blockade in cancer therapy

\begin{tabular}{|c|c|c|c|}
\hline Tumor & Target IC & Result & References \\
\hline Hepatocellular carcinoma & PD-1 & $\begin{array}{l}\text { Inhibition of tumor growth and lung metastasis along with improved OS rate in mice } \\
\text { models }\end{array}$ & {$[231]$} \\
\hline Triple-negative breast cancer & PD-L1 & Robust antitumor effect and extended OS rate in 4T1 cell bearing murine model & {$[235]$} \\
\hline Ovarian cancer & PD-1 & $\begin{array}{l}\text { Enhancing the effector T-cell infiltration, improving effector T-cell function and also } \\
\text { memory T cells in TME } \\
\text { Reducing intratumoral Treg cells and promoting the conversion of Treg cells into T helper } \\
\text { Improved OS rate in mice model }\end{array}$ & {$[233]$} \\
\hline Glioblastoma & PD-1 & $\begin{array}{l}\text { Improving the memory } T \text { cells and reducing MDSCs } \\
\text { Promoting CD } 4+/ C D 8+\text { ratios in the brain and elevation of pro-inflammatory cytokines } \\
\text { levels in the brain }\end{array}$ & {$[36]$} \\
\hline Pancreatic ductal adenocarcinoma & PD-1 & $\begin{array}{l}\text { Inspiring the CD } 8+\text { T-cell migration into the juxtatumoral compartment and also induc- } \\
\text { tion apoptosis in tumor cell }\end{array}$ & [237] \\
\hline Osteosarcoma & PD-1 & Inducing tumor regression by suppressing MDSCs in mice model & {$[232]$} \\
\hline $\begin{array}{l}\text { Colon cancer } \\
\text { Melanoma }\end{array}$ & PD-1 & $\begin{array}{l}\text { Inhibition of tumor growth in two syngeneic murine models, by improving granzyme } \\
\text { and suppressing FOXP3 cells infiltration }\end{array}$ & {$[236]$} \\
\hline Ovarian cancer & PD-1 & Improved OS rate in treated mice model & {$[234]$} \\
\hline Lung cancer & PD-L1 & $\begin{array}{l}\text { Improving the T cell infiltration, enhancing expression of calreticulin on tumor cells } \\
\text { Reducing MDSCs and Treg in the TME }\end{array}$ & {$[274]$} \\
\hline Glioblastoma & PD-1 & $\begin{array}{l}\text { Demonstrating immune memory concurrently reducing populations of MDSCs and } \\
\text { tumor-promoting immune cells } \\
\text { Improved OS rate in treated mice model }\end{array}$ & {$[275]$} \\
\hline Triple-negative breast cancer & PD-L1 & $\begin{array}{l}\text { Promoting the tumor immunogenicity to recruit } T \text { cells, attenuating the physiological } \\
\text { barricades of intratumoral fibrosis and collagen to support } T \text { cell infiltration, and reducing } \\
\text { the immunosuppressive cells to revive } T \text { cells }\end{array}$ & {$[276]$} \\
\hline Melanoma & PD-1 & $\begin{array}{l}\text { Modulating the immune cell profile within the TME and improving CD8 + T cell infiltra- } \\
\text { tion }\end{array}$ & {$[277]$} \\
\hline
\end{tabular}


Table 4 Clinical trials result based on combination therapy with ICls and other modalities

\begin{tabular}{|c|c|c|c|}
\hline Tumor & Agent (s) & Result (s) & References \\
\hline \multicolumn{4}{|l|}{$\mathrm{ICI}$ plus Anti-anti-angiogenic agent } \\
\hline Triple-negative breast cancer & SHR-1210 plus Apatinib & $\begin{array}{l}\text { Notable tolerability and efficacy } \\
\text { Higher TGF- } \beta \text { expressions associated with } \\
\text { favorable prognosis }\end{array}$ & [278] \\
\hline Renal cell carcinoma & Atezolizumab plus Bevacizumab & $\begin{array}{l}\text { Enhancement in intratumoral CTL cells, and } \\
\text { also intra-tumoral MHC-I, Th1, and T-effector } \\
\text { markers, and CX3CL1 }\end{array}$ & [279] \\
\hline Melanoma & Ipilimumab plus Bevacizumab & $\begin{array}{l}\text { Remarkable safety and tolerability } \\
\text { Modification in tumor vasculature and immune } \\
\text { responses and alteration of lymphocyte traffick- } \\
\text { ing, and immune regulation }\end{array}$ & {$[280]$} \\
\hline Ovarian cancer & Nivolumab plus Bevacizumab & $\begin{array}{l}\text { Anti-tumor activity, in particular, in the } \\
\text { platinum-sensitive setting }\end{array}$ & [173] \\
\hline Renal cell carcinoma & Nivolumab plus Sunitinib & $\begin{array}{l}\text { Remarkable irAEs along with no improvement } \\
\text { in the OS }\end{array}$ & [281] \\
\hline Colorectal cancer & Atezolizumab plus Bevacizumab & $\begin{array}{l}\text { Without unexpected adverse events or severe } \\
\text { toxicities }\end{array}$ & [282] \\
\hline Renal cell carcinoma & Pembrolizumab plus Axitinib & $\begin{array}{l}\text { Notable tolerability and efficacy along with no } \\
\text { unexpected toxicities }\end{array}$ & [33] \\
\hline Melanoma & Ipilimumab plus Bevacizumab & Improved OS & [283] \\
\hline Sarcoma & Nivolumab plus Sunitinib & Improved PFS & [284] \\
\hline Non-small cell lung carcinoma & Sintilimab plus Anlotinib & $\begin{array}{l}\text { Robust efficacy, durability, and safety profile } \\
\text { Improved PFS }\end{array}$ & [285] \\
\hline Advanced solid tumors & Pembrolizumab plus Lenvatinib & $\begin{array}{l}\text { Manageable safety profile and favorable antitu- } \\
\text { mor activity }\end{array}$ & [286] \\
\hline Renal cell carcinoma & Nivolumab plus Cabozantinib & Improved PFS and OS & {$[287]$} \\
\hline $\begin{array}{l}\text { Lymphoma } \\
\text { Solid tumors }\end{array}$ & Ipilimumab and Lenalidomide & $\begin{array}{l}\text { Significant tolerability concomitantly prelimi- } \\
\text { nary signals of anti-tumor activity }\end{array}$ & [288] \\
\hline Non-small cell lung carcinoma & Nivolumab plus Bevacizumab & Improved PFS and ORR & [289] \\
\hline \multicolumn{4}{|l|}{ ICl plus Chemotherapeutic agent } \\
\hline Non-small cell lung carcinoma & $\begin{array}{l}\text { Nivolumab plus Ipilimumab and Platinum- } \\
\text { based compound }\end{array}$ & $\begin{array}{l}\text { Improved OS versus chemotherapy alone and } \\
\text { also favorable risk-benefit profile }\end{array}$ & [290] \\
\hline Solid tumors & Cemiplimab plus RT and CTX & Acceptable safety but no efficacy & [268] \\
\hline Non-small cell lung carcinoma & $\begin{array}{l}\text { Pembrolizumab plus Carboplatin and Pem- } \\
\text { etrexed }\end{array}$ & Improved OS and PFS & [291] \\
\hline Non-small cell lung carcinoma & Nivolumab plus Platinum-based compound & Improved OS & [291] \\
\hline Non-small cell lung carcinoma & Ipilimumab plus Paclitaxel and Carboplatin & Improved OS and PFS with manageable irAEs & [292] \\
\hline Mesothelioma & Nivolumab plus Cisplatin and Pemetrexed & $\begin{array}{l}\text { Some irAEs such as severe abdominal disten- } \\
\text { tion }\end{array}$ & [293] \\
\hline Pancreatic cancer & Ipilimumab plus Gemcitabine & $\begin{array}{l}\text { No superiority over chemotherapy with gem- } \\
\text { citabine }\end{array}$ & [294] \\
\hline Biliary tract cancer & Nivolumab plus Gemcitabine and Cisplatin & $\begin{array}{l}\text { Improved OS and PFS with manageable irAEs } \\
\text { FasL, MCP-1, and INF- } \gamma \text { associated with favora- } \\
\text { ble prognosis }\end{array}$ & [149] \\
\hline Pancreatic ductal adenocarcinoma & $\begin{array}{l}\text { Nivolumab (Nivo) plus nab-Paclitaxel and } \\
\text { Gemcitabine }\end{array}$ & $\begin{array}{l}\text { Improved OS along with severe irAEs such as } \\
\text { pneumonitis in some case }\end{array}$ & [295] \\
\hline Urothelial cancer & Pembrolizumab plus Docetaxel or Gemcitabine & Improved PFS and ORR & [296] \\
\hline Melanoma & Ipilimumab plus Dacarbazine & $\begin{array}{l}\text { No tolerability along with high-grade liver } \\
\text { toxicities }\end{array}$ & [297] \\
\hline \multicolumn{4}{|l|}{ ICI plus Radiotherapy } \\
\hline Melanoma & Ipilimumab plus RT & Synergetic anti-tumor response & [298] \\
\hline Melanoma & Ipilimumab plus RT & A systemic complete response & [299] \\
\hline Prostate cancer & Ipilimumab plus RT & Complete response in 1 participant only & [300] \\
\hline Advanced solid tumors & Nivolumab plus Ipilimumab and RT & $\begin{array}{l}\text { Acceptable tolerability along with manageable } \\
\text { irAEs }\end{array}$ & [212] \\
\hline
\end{tabular}


Table 4 (continued)

\begin{tabular}{|c|c|c|c|}
\hline Tumor & Agent (s) & Result (s) & References \\
\hline Advanced solid tumors & Durvalumab plus RT & Acceptable tolerability without abscopal effect & [301] \\
\hline $\begin{array}{l}\text { Renal cell carcinoma } \\
\text { Melanoma }\end{array}$ & Nivolumab plus Ipilimumab and RT & $\begin{array}{l}\text { Significant improvement in ORR and OS } \\
\text { Any grade irAEs in } 46 \text { of } 59 \text { patients }\end{array}$ & [211] \\
\hline Non-small cell lung carcinoma & Pembrolizumab plus RT & $\begin{array}{l}\text { Improvement in ORR and OS with an accept- } \\
\text { able safety profile }\end{array}$ & [91] \\
\hline \multicolumn{4}{|l|}{$\mathrm{ICI}$ plus Cancer vaccines } \\
\hline Melanoma & Ipilimumab plus T-VEC & Improved ORR & {$[302]$} \\
\hline Melanoma & Ipilimumab plus T-VEC & Improved ORR & [303] \\
\hline Prostate cancer & Ipilimumab plus Sipuleucel-T & Acceptable tolerability & [304] \\
\hline Prostate cancer & Ipilimumab plus Sipuleucel-T & Improved OS & [304] \\
\hline Prostate cancer & Ipilimumab plus GVAX & Improved OS & {$[305]$} \\
\hline Prostate cancer & Ipilimumab plus GVAX & Manageable irAEs & [306] \\
\hline Pancreatic ductal adenocarcinoma & Ipilimumab plus GVAX & $\begin{array}{l}\text { Prolonged disease stabilization and a trend of } \\
\text { favorable median OS }\end{array}$ & [200] \\
\hline Melanoma & Ipilimumab plus Peptide vaccine & Durable ORR & {$[307]$} \\
\hline Melanoma & Ipilimumab plus Peptide vaccine & No difference in median OS & [308] \\
\hline Melanoma & Pembrolizumab plus T-VEC and RT & No significant effect & [309] \\
\hline Melanoma & Nivolumab or Ipilimumab plus T-VEC & Potentiating the antitumor effect of T-VEC & [310] \\
\hline Pancreatic ductal adenocarcinoma & Nivolumab plus GVAX and CTX & Improved ORR without any effect on OS & {$[311,312]$} \\
\hline Melanoma & Nivolumab plus Gp100 & Acceptable tolerability & [313] \\
\hline \multicolumn{4}{|l|}{$\mathrm{ICl}$ plus Other modalities } \\
\hline Triple-negative breast cancer & Durvalumab plus Olaparib & $\begin{array}{l}\text { Acceptable tolerability along with preliminary } \\
\text { activity in recurrent cancers }\end{array}$ & {$[314]$} \\
\hline Ovarian cancer & Durvalumab plus Olaparib & Modest clinical activity & {$[315]$} \\
\hline Melanoma & Pembrolizumab plus Dabrafenib and Trametinib & Enhanced anti-tumor responses & [316] \\
\hline Renal cell carcinoma & Nivolumab plus Mavorixafor & $\begin{array}{l}\text { Potential antitumor activity and a manageable } \\
\text { safety profile }\end{array}$ & [239] \\
\hline
\end{tabular}

ICl immune checkpoint inhibitor, CTLs cytotoxic T cells, IFN interferon, OS overall survival, ORR objective response rate, PFS progression-free survival, irAEs immune related adverse events, $M C P-1 / C C L 2$ monocyte chemoattractant protein-1, $R T$ radiotherapy

$\mathrm{T}$ cell infiltration and IFN- $\gamma$ production in tumor cellbearing mice, underlying delayed tumor growth [217]. As well, a clinical trial in 13 patients with metastatic melanoma revealed that combined use of ipilimumab $(3 \mathrm{mg} /$ $\mathrm{kg})$ plus TIL might induce significant ORR (38.5\%) and promoted PFS (7.3 months) [218]. Co-administration of the TILs with ipilimumab or nivolumab into 6 patients with ovarian cancer also supported a partial response in 1 patient, while 5 others experienced disease stabilization for up to 1 year [219]. In another report, targeted delivery of PD-1-blocking single-chain variable fragments (scFv) by CAR-T cells potentiated anti-tumor immunity in vivo, as evidenced by Rafiq et al. reports [220].

In 2017, Shaw et al. found that in HNSCC murine models, co-administration of HER2-redirected CAR-T cell plus PD-1 inhibitor substantially improved survival compared to monotherapy with each of them [221]. Similarly, anti-EGFR variant III CAR-T cell therapy in association with anti-PD-1 mAb could exert more efficient and persistent therapeutic influences on GBM and also stimulate an intensified number of TILs in vivo [222].
Besides, combined use of the mesothelin-specific CAR-T cells with PD-1 inhibitor exhibited substantial safety and modest efficacy (as shown by improved OS) in 18 patients with MPM [223, 224]. However, it seems that the execution of large-scale studies is required to address the reliable efficacy of this intervention in MPM patients. Besides, anti-CD19 CAR T cells plus pembrolizumab enhanced and/or prolonged detection of circulating CAR T cells and also resulted in ORR (50\%) in leukemia patients (NCT02374333, NCT02906371) [225].

\section{ICls with CXCR4 inhibitors}

Overexpression of C-X-C chemokine receptor (CXCR) 4 is allied with undesired prognosis in human several tumors [226, 227]. Hence, CXCL12 (SDF-1)/CXCR-4 signaling pathway has been described as a rational and effective therapeutic target in the context of tumor therapy due to its pivotal role in tumor instigation and development by triggering various signaling pathways, comprising ERK1/2, Ras, JNK and p38 MAPK along with adjusting CSCs [228]. As a result, CXCL12/CXCR4 
Table 5 A summary of clinical trials based on combination therapy with ICls plus other modalities in human cancers registered in https://clinicaltrials.gov (October 2021)

\begin{tabular}{|c|c|c|c|c|c|}
\hline Condition & Agents & Study phase & $\begin{array}{l}\text { Participant } \\
\text { number }\end{array}$ & Study location & NCT number \\
\hline Non-small-cell lung carcinoma & Platinum + Durvalumab & 2 & 55 & USA & NCT04062708 \\
\hline $\begin{array}{l}\text { Solid tumor } \\
\text { Hematological malignancy }\end{array}$ & Eliglustat $+\mathrm{ICl}$ & 1 & 30 & China & NCT04944888 \\
\hline Advanced tumors & $\begin{array}{l}\text { Ipilimumab, Nivolumab, Pembroli- } \\
\text { zumab + BB|608 }\end{array}$ & $1 / 2$ & 104 & USA & NCT02467361 \\
\hline Non-small-cell lung carcinoma & Tocilizumab + Atezolizumab & $1 / 2$ & 28 & USA & NCT04691817 \\
\hline Non-small-cell lung carcinoma & $\begin{array}{l}\text { Platinum + angiogenesis inhibitors } \\
\text { and } \mathrm{ICI}\end{array}$ & NA & 126 & China & NCT04137588 \\
\hline $\begin{array}{l}\text { Hepatocellular carcinoma } \\
\text { Biliary tract cancer }\end{array}$ & Nivolumab + Pembrolizumab & NA & 100 & Republic of Korea & NCT03695952 \\
\hline Pancreatic cancer & $\mathrm{RT}+\mathrm{ICl}$ & $1 / 2$ & 52 & USA & NCT04327986 \\
\hline Advanced solid tumors & ASP8374 + Pembrolizumab & 1 & 169 & USA & NCT03260322 \\
\hline $\begin{array}{l}\text { Solid tumor } \\
\text { Lymphoma }\end{array}$ & Ad-p53 Gene Therapy + ICl & 2 & 40 & USA & NCT03544723 \\
\hline Multiple primary lung cancer & Microwave ablation + Camrelizumab & 2 & 146 & China & NCT05053802 \\
\hline Advanced solid tumors & $\mathrm{FT} 500+\mathrm{ICl}$ & 1 & 76 & USA & NCT03841110 \\
\hline Advanced solid tumors & DSP-7888 Dosing Emulsion $+\mathrm{ICI}$ & $1 / 2$ & 84 & USA & NCT03311334 \\
\hline Intrahepatic cholangiocarcinoma & $\mathrm{ICI}+$ Lenvatinib and Sintilimab & 2 & 25 & China & NCT05010681 \\
\hline Solid tumors & Gut Microbiome + $\mid \mathrm{Cl}$ & NA & 800 & USA & NCT05037825 \\
\hline Non-small-cell lung carcinoma & ICI+OSE2101, Docetaxel, Pemetrexed & 3 & 363 & USA & NCT02654587 \\
\hline Genitourinary cancer Melanoma & Infliximab or Vedolizumab + |Cl & $1 / 2$ & 100 & USA & NCT04407247 \\
\hline Non-small-cell lung carcinoma & Pembrolizumab + RT & $1 / 2$ & 164 & International & NCT03996473 \\
\hline Non-small-cell lung carcinoma & Ramucirumab + Atezolizumab & 2 & 21 & USA & NCT05007769 \\
\hline Non-small-cell lung carcinoma & Ipilimumab + Nivolumab & 3 & 1360 & France & NCT03469960 \\
\hline Renal cell carcinoma & Atezolizumab + Cabozantinib & 3 & 500 & International & NCT04338269 \\
\hline Cervical cancer & BAVC-C + Durvalumab & 2 & 37 & Republic of Korea & NCT04800978 \\
\hline Cervical cancer & Pembrolizumab + Platinum and RT & 1 & 1 & United Kingdom & NCT03144466 \\
\hline $\begin{array}{l}\text { Squamous cell carcinoma of head and } \\
\text { neck }\end{array}$ & Nivolumab + Surgical resection & 2 & 24 & USA & NCT03878979 \\
\hline Non-small-cell lung carcinoma & Atezolizumab + RT & 1 & 2 & USA & NCT02599454 \\
\hline Advanced solid tumors & Nivolumab + Copanlisib & $1 / 2$ & 102 & USA & NCT04317105 \\
\hline Inoperable esophageal Cancer & $\begin{array}{l}\text { Nivolumab, Ipilimumab + Chemoradia- } \\
\text { tion }\end{array}$ & 2 & 103 & France & NCT03437200 \\
\hline Non-small-cell lung carcinoma & Ramucirumab + SAR408701 & 2 & 36 & USA & NCT04394624 \\
\hline Hepatocellular carcinoma & Pembrolizumab + Regorafenib & 2 & 119 & USA & NCT04696055 \\
\hline Lung cancer & Pembrolizumab + Idelalisib & $1 / 2$ & 40 & USA & NCT03257722 \\
\hline Metastatic colorectal cancer & Atezolizumab + Bevacizumab and RT & 2 & 52 & France & NCT04659382 \\
\hline Advanced solid cancers & $\begin{array}{l}\text { Ipilimumab, Nivolumab + Copanlisib } \\
\text { Hydrochloride }\end{array}$ & $1 / 2$ & 102 & USA & NCT04317105 \\
\hline Esophageal cancer & $\begin{array}{l}\text { Nivolumab, Ipilimumab + Chemoradia- } \\
\text { tion }\end{array}$ & 2 & 130 & France & NCT03437200 \\
\hline Non-small-cell lung carcinoma & Ramucirumab + Atezolizumab & 2 & 21 & USA & NCT03689855 \\
\hline Castration-resistant prostate cancer & Pembrolizumab + HER2Bi-armed & 2 & 33 & USA & NCT03406858 \\
\hline Advanced solid tumors & $\mathrm{ICl}+\mathrm{RT}$ & NA & 200 & Germany & NCT04892849 \\
\hline $\begin{array}{l}\text { Liver-dominant Metastatic colorectal } \\
\text { cancer }\end{array}$ & Atezolizumab + RT, Bevacizumab & 2 & 52 & France & NCT04659382 \\
\hline
\end{tabular}

$\mathrm{ICl}$ immune checkpoint inhibitor, $R T$ radiotherapy 
antagonists have currently been developed to impair pathological procedures and also disrupt cancer cell adhesion to the stromal cells [229, 230]. Disrupting such adhesions ultimately facilitate the cancer cells' mobilization into the systemic circulation and can offer an appreciated opportunity to eradicate these cell by other modalities, such as cytotoxic chemotherapeutic agents [231]. Recent reports displayed that promotion of the CXCL12 expression in HCC models improved hypoxia, and also induced the recruitment of immunosuppressive cells, whereas PD-1 inhibitor along with CXCR4 inhibition and sorafenib reduced HCC growth [231]. Dual targeting CXCR4 and PD-1 also sustained the TILs population as well as their activation in the glioma microenvironment [36]. Targeting MDSCs with CXCR4 blockade potentiated anti-PD-1 to uphold antitumor immune reactions and ameliorated OS in glioma cell-bearing mice [36]. Another important study has demonstrated that tumor-infiltrating MDSCs usually are CXCR4 positive and could migrate toward the CXCL12 gradient [232]. Given that CXCL12/CXCR4 interaction leads typically to the induction of the AKT pathway and afterward compromises MDSCs apoptosis, Jiang and coworkers suggested that plerixafor (AMD3100), a highly specific CXCR4 antagonist, could provoke a synergistic influence with anti-PD-1 antibody to enable tumor regression in a murine model of osteosarcoma [232]. Also, addition of AMD3100 to PD-1 inhibitor potently delayed tumor development and prolonged OS in ovarian cancer murine model more prominently than single-agent administration [233]. Furthermore, the intervention was accompanied by augmented effector T-cell infiltration as well as function concomitant with heightened memory $\mathrm{T}$ cells in TME [233]. Combination therapy also resulted in reduced intratumoral Tregs and also MDSCs allied with reduced IL-10 and IL- 6 in the ascites and simultaneously induced M2-to-M1 macrophage polarization in the tumor [233]. Of course, some reports signified that CXCR4 blockade might stimulate the proportion of circulating myeloid cells during active treatment in the ovarian cancer mice model, thereby additional examination into this novel therapeutic method is warranted [234]. On the other hand, dual-targeting PD-L1 and CXCR4 showed an amplified antitumor outcome, reduced Tregs infiltration, and extended OS compared with monotherapies in 4T1 TNBC [235], MC38 colon cancer [236] and B16 melanoma cell [236] xenografts. These data offered proof of the concept that CXCR4 inhibitors have pronounced capacities to expand ICI therapies to originally ICI-insensitive tumor types. Further, treatment of fresh human PDAC specimens with PD-1 and CXCR4 inhibitors gave rise to enhanced tumor cell death and also lymphocyte expansion [237]. Also, another clinical trial
(NCT04543071) is ongoing to address the safety and efficacy of combination therapy with chemotherapeutic agents (gemcitabine and nab-paclitaxel) with CXCR4 inhibitor (motixafortide), and PD-1 inhibitor (cemiplimab) in patients with metastatic PDAC [238]. Besides, combined use of mavorixafor (X4P-001) as an allosteric CXCR4 inhibitor plus nivolumab in 9 patients with advanced RCC showed acceptable antitumor effect and a manageable safety profile (NCT02923531) [239, 240]. As well, it was supposed that enhancement in levels of CXCL9 correlates with clinical benefit [239].

A summary of conducted studies respecting combination therapy with ICIs and CXCR4 blockade therapy have been listed in (Tables 3 and 4).

\section{Conclusion and prospect}

As shown in clinical trials (Tables 4 and 5), addition of ICIs to other therapeutic means has been shown encouraging outcomes to treat even metastatic tumors with unfavorable prognosis. However, the intervention-associated irAEs can hurdle their application in the clinic. Skin and colon are the most common organs, while the normal activity of lungs, kidneys, liver, and also heart mainly impaired by ICIs alone or in combination therapies [241]. Though, corticosteroids are usually exploited to ameliorate moderate and severe irAEs, additional immunosuppressive drugs may sometimes be prerequisite $[242,243]$. Also, much efforts have recently been spent to determine predictive biomarkers for ICIs response [244]. Meanwhile, PD-L1 expression, microsatellite instability (MSI), high tumor mutational burden (TMB) along with CD8 infiltrates are noted as foremost predictive markers for ICIs response [245-247]. Taken together, we propose that fulfilling of large-scale trials with further attention to the predictive biomarkers can durably arouse more preferred outcomes with manageable irAEs.

\section{Acknowledgements \\ Not applicable. \\ Authors' contributions \\ All authors contributed to the conception and the main idea of the work. SV, AOZ, BAZ, RAK, AG, and HA drafted the main text, figures, and tables. MZ supervised the work and provided comments and additional scientific infor- mation. SV, AG, and BAZ also reviewed and revised the text. All authors read and approved the final version of the work to be published.}

\section{Funding \\ No Funders.}

Availability of data and materials

Not applicable.

\section{Declarations}

Ethics approval and consent to participate Not applicable. 


\section{Consent for publication \\ Not applicable.}

\section{Competing interests}

There is no conflict of interests.

\begin{abstract}
Author details
${ }^{1}$ Department of Molecular Medicine, Faculty of Advanced Technologies in Medicine, Iran University of Medical Sciences, Tehran, Iran. ${ }^{2}$ Department of Prosthetic Dentistry, I. M. Sechenov First Moscow State Medical University, Moscow, Russia. ${ }^{3}$ Internal Medicine and Surgery Department, College of Veterinary Medicine, University of Duhok, Kurdistan Region, Iraq. ${ }^{4}$ Basic Sciences Department, College of Pharmacy, University of Duhok, Kurdistan Region, Iraq. ${ }^{5}$ Medicine Faculty, Hacettepe University, Ankara, Turkey. ${ }^{6}$ Medicine Faculty, Cerrahpasa University, Istanbul, Turkey. ${ }^{7}$ Department of Medical Laboratory Sciences, Faculty of Allied Medicine, Infectious Diseases Research Center, Gonabad University of Medical Sciences, Gonabad, Iran.
\end{abstract}

Received: 14 November 2021 Accepted: 10 December 2021

Published online: 03 January 2022

\section{References}

1. Ashrafizadeh M, Farhood B, Musa AE, Taeb S, Rezaeyan A, Najafi M. Abscopal effect in radioimmunotherapy. Int Immunopharmacol. 2020;85:106663.

2. Kruger S, Ilmer M, Kobold S, Cadilha BL, Endres S, Ormanns S, et al. Advances in cancer immunotherapy 2019-latest trends. J Exp Clin Cancer Res. 2019;38(1):268.

3. Hanfei G, Rilan B, Jiuwei C. Advances in combination therapy of immune checkpoint inhibitors for lung cancer. Chin J Lung Cancer. 2020;23(2).

4. Pardoll DM. The blockade of immune checkpoints in cancer immunotherapy. Nat Rev Cancer. 2012;12(4):252-64

5. Byun DJ, Wolchok JD, Rosenberg LM, Girotra M. Cancer immunotherapy_immune checkpoint blockade and associated endocrinopathies. Nat Rev Endocrinol. 2017;13(4):195-207.

6. Walunas TL, Bakker CY, Bluestone JA. CTLA-4 ligation blocks CD28dependent T cell activation. J Exp Med. 1996;183(6):2541-50.

7. Greenwald RJ, Boussiotis VA, Lorsbach RB, Abbas AK, Sharpe AH. CTLA-4 regulates induction of anergy in vivo. Immunity. 2001;14(2):145-55.

8. Sondak VK, Smalley KS, Kudchadkar R, Grippon S, Kirkpatrick P. Ipilimumab. Nat Rev Drug Discovery. 2011;10(6):411-3.

9. Simpson TR, Li F, Montalvo-Ortiz W, Sepulveda MA, Bergerhoff K, Arce $F$, et al. Fc-dependent depletion of tumor-infiltrating regulatory $T$ cells co-defines the efficacy of anti-CTLA-4 therapy against melanoma. J Exp Med. 2013;210(9):1695-710.

10. Read S, Greenwald R, Izcue A, Robinson N, Mandelbrot D, Francisco L, et al. Blockade of CTLA-4 on CD4+ CD25+ regulatory T cells abrogates their function in vivo. J Immunol. 2006;177(7):4376-83.

11. Freeman GJ, Long AJ, Iwai $Y$, Bourque $K$, Chernova T, Nishimura $H$, et al. Engagement of the PD-1 immunoinhibitory receptor by a novel B7 family member leads to negative regulation of lymphocyte activation. $J$ Exp Med. 2000;192(7):1027-34

12. Chen L, Han X. Anti-PD-1/PD-L1 therapy of human cancer: past, present, and future. J Clin Investig. 2015;125(9):3384-91.

13. Zhang X, Zeng Y, Qu Q, Zhu J, Liu Z, Ning W, et al. PD-L1 induced by IFN- $\gamma$ from tumor-associated macrophages via the JAK/STAT3 and PI3K AKT signaling pathways promoted progression of lung cancer. Int J Clin Oncol. 2017;22(6):1026-33.

14. Chen J, Feng Y, Lu L, Wang H, Dai L, Li Y, et al. Interferon- $\gamma$-induced PD-L1 surface expression on human oral squamous carcinoma via PKD2 signal pathway. Immunobiology. 2012;217(4):385-93.

15. Imai Y, Chiba T, Kondo T, Kanzaki H, Kanayama K, Ao J, et al. Interferon- $\gamma$ induced PD-L1 expression and soluble PD-L1 production in gastric cancer. Oncol Lett. 2020;20(3):2161-8.

16. Sunshine J, Taube JM. Pd-1/pd-11 inhibitors. Curr Opin Pharmacol. 2015;23:32-8
17. Yu JX, Hodge JP, Oliva C, Neftelinov ST, Hubbard-Lucey VM, Tang J. Trends in clinical development for PD-1/PD-L1 inhibitors. Nat Rev Drug Discov. 2020:19(3):163-4.

18. Fares CM, Van Allen EM, Drake CG, Allison JP, Hu-Lieskovan S. Mechanisms of resistance to immune checkpoint blockade: why does checkpoint inhibitor immunotherapy not work for all patients? Am Soc Clin Oncol Educ Book. 2019:39:147-64.

19. Schoenfeld AJ, Hellmann MD. Acquired resistance to immune checkpoint inhibitors. Cancer Cell. 2020;37(4):443-55.

20. Marin-Acevedo JA, Chirila RM, Dronca RS, editors. Immune checkpoint inhibitor toxicities. Mayo Clinic Proceedings; 2019: Elsevier.

21. Jenkins RW, Barbie DA, Flaherty KT. Mechanisms of resistance to immune checkpoint inhibitors. Br J Cancer. 2018;118(1):9-16.

22. Pulluri B, Kumar A, Shaheen M, Jeter J, Sundararajan S. Tumor microenvironment changes leading to resistance of immune checkpoint inhibitors in metastatic melanoma and strategies to overcome resistance. Pharmacol Res. 2017;123:95-102.

23. Barrueto L, Caminero F, Cash L, Makris C, Lamichhane P, Deshmukh RR. Resistance to checkpoint inhibition in cancer immunotherapy. Transl Oncol. 2020;13(3):100738.

24. Galluzzi L, Humeau J, Buqué A, Zitvogel L, Kroemer G. Immunostimulation with chemotherapy in the era of immune checkpoint inhibitors. Nat Rev Clin Oncol. 2020;17(12):725-41.

25. Soliman HH. nab-Paclitaxel as a potential partner with checkpoint inhibitors in solid tumors. Onco Targets Ther. 2017;10:101.

26. Falvo P, Orecchioni S, Hillje R, Raveane A, Mancuso P, Camisaschi C, et al. Cyclophosphamide and vinorelbine activate stem-like CD8+T cells and improve anti-PD-1 efficacy in triple-negative breast cancer. Can Res. 2021;81(3):685-97.

27. Sindoni A, Minutoli F, Ascenti G, Pergolizzi S. Combination of immune checkpoint inhibitors and radiotherapy: review of the literature. Crit Rev Oncol Hematol. 2017;113:63-70.

28. Derer A, Frey B, Fietkau R, Gaipl US. Immune-modulating properties of ionizing radiation: rationale for the treatment of cancer by combination radiotherapy and immune checkpoint inhibitors. Cancer Immunol Immunother. 2016;65(7):779-86.

29. Van Elsas A, Hurwitz AA, Allison JP. Combination immunotherapy of B16 melanoma using anti-cytotoxic T lymphocyte-associated antigen 4 (CTLA-4) and granulocyte/macrophage colony-stimulating factor (GM-CSF)-producing vaccines induces rejection of subcutaneous and metastatic tumors accompanied by autoimmune depigmentation. J Exp Med. 1999:190(3):355-66.

30. Zhao J, Chen Y, Ding Z-Y, Liu J-Y. Safety and efficacy of therapeutic cancer vaccines alone or in combination with immune checkpoint inhibitors in cancer treatment. Front Pharmacol. 2019;10:1184

31. Tobias J, Battin C, De Sousa LA, Lebens M, Baier K, Ambroz K, et al. A new strategy toward $B$ cell-based cancer vaccines by active immunization with mimotopes of immune checkpoint inhibitors. Front Immunol. 2020;11:895.

32. Choueiri TK, Larkin JM, Oya M, Thistlethwaite FC, Martignoni M, Nathan PD, et al. First-line avelumab + axitinib therapy in patients (pts) with advanced renal cell carcinoma (aRCC): results from a phase Ib trial. Am Soc Clin Oncol: 2017.

33. Atkins MB, Plimack ER, Puzanov I, Fishman MN, McDermott DF, Cho DC, et al. Axitinib in combination with pembrolizumab in patients with advanced renal cell cancer: a non-randomised, open-label, dose-finding, and dose-expansion phase $1 \mathrm{~b}$ trial. Lancet Oncol. 2018;19(3):405-15.

34. Amin A, Plimack ER, Infante JR, Ernstoff MS, Rini BI, McDermott DF, et al. Nivolumab (anti-PD-1; BMS-936558, ONO-4538) in combination with sunitinib or pazopanib in patients (pts) with metastatic renal cell carcinoma (mRCC). Am Soc Clin Oncol; 2014.

35. Meric-Bernstam F, Johnson AM, Dumbrava EEl, Raghav K, Balaji K, Bhatt $M$, et al. Advances in HER2-targeted therapy: novel agents and opportunities beyond breast and gastric cancer. Clin Cancer Res. 2019:25(7):2033.

36. Wu A, Maxwell R, Xia Y, Cardarelli P, Oyasu M, Belcaid Z, et al. Combination anti-CXCR4 and anti-PD-1 immunotherapy provides survival benefit in glioblastoma through immune cell modulation of tumor microenvironment. J Neurooncol. 2019;143(2):241-9. 
37. Starbuck K, McGray R, Masoumi-Moghaddam S, Francois A, Odunsi K, Zsiros E. CXCR4 in combination with immune check point inhibition in ovarian cancer mouse model demonstrates potential for novel therapeutic strategies. AACR; 2017.

38. Ni J, Ni A. Landscape of PD-1/PD-L1 regulation and targeted immunotherapy. Chin Med Sci J. 2018;33(3):174-82.

39. Cretella D, Digiacomo G, Giovannetti E, Cavazzoni A. PTEN alterations as a potential mechanism for tumor cell escape from PD-1/PD-L1 inhibition. Cancers. 2019:11(9):1318.

40. Toor SM, Nair VS, Decock J, Elkord E, editors. Immune checkpoints in the tumor microenvironment. Seminars in cancer biology; 2020: Elsevier.

41. Vermeulen JF, Van Hecke W, Adriaansen EJ, Jansen MK, Bouma RG, Villacorta Hidalgo J, et al. Prognostic relevance of tumor-infiltrating lymphocytes and immune checkpoints in pediatric medulloblastoma. Oncoimmunology. 2018;7(3):e1398877.

42. Beyersdorf N, Kerkau T, Hünig T. CD28 co-stimulation in T-cell homeostasis: a recent perspective. ImmunoTargets Ther. 2015;4:111.

43. Chambers CA, Allison JP. Co-stimulation in T cell responses. Curr Opin Immunol. 1997;9(3):396-404.

44. Acuto O, Michel F. CD28-mediated co-stimulation: a quantitative support for TCR signalling. Nat Rev Immunol. 2003;3(12):939-51.

45. Walunas TL, Lenschow DJ, Bakker CY, Linsley PS, Freeman GJ, Green JM, et al. CTLA-4 can function as a negative regulator of T cell activation. Immunity. 1994;1(5):405-13.

46. Lee K-M, Chuang E, Griffin M, Khattri R, Hong DK, Zhang W, et al. Molecular basis of T cell inactivation by CTLA-4. Science. 1998:282(5397):2263-6.

47. Brunner-Weinzierl MC, Rudd CE. CTLA-4 and PD-1 control of T-cell motility and migration: implications for tumor immunotherapy. Front Immunol. 2018;9:2737.

48. Bengsch F, Knoblock DM, Liu A, McAllister F, Beatty GL. CTLA-4/CD80 pathway regulates $T$ cell infiltration into pancreatic cancer. Cancer Immunol Immunother. 2017:66(12):1609-17.

49. Salvi S, Fontana $V$, Boccardo S, Merlo DF, Margallo E, Laurent S, et al. Evaluation of CTLA-4 expression and relevance as a novel prognostic factor in patients with non-small cell lung cancer. Cancer Immunol Immunother. 2012;61(9):1463-72.

50. Erfani N, Mehrabadi SM, Ghayumi MA, Haghshenas MR, Mojtahedi Z, Ghaderi A, et al. Increase of regulatory $T$ cells in metastatic stage and CTLA-4 over expression in lymphocytes of patients with non-small cell lung cancer (NSCLC). Lung Cancer. 2012;77(2):306-11.

51. Lafuente-Sanchis A, Zúñiga Á, Estors M, Martínez-Hernández NJ, Cremades A, Cuenca M, et al. Association of PD-1, PD-L1, and CTLA-4 gene expression and clinicopathologic characteristics in patients with non-small-cell lung cancer. Clin Lung Cancer. 2017;18(2):e109-16.

52. Khalife E, Khodadadi A, Talaeizadeh A, Rahimian L, Nemati M, Jafarzadeh A. Overexpression of regulatory T cell-related markers (FOXP3, CTLA-4 and GITR) by peripheral blood mononuclear cells from patients with breast cancer. Asian Pac J Cancer Prevent. 2018;19(11):3019.

53. Kern R, Panis C. CTLA-4 expression and its clinical significance in breast cancer. Arch Immunol Ther Exp. 2021;69(1):1-9.

54. Huang P-Y, Guo S-S, Zhang Y, Lu J-B, Chen Q-Y, Tang L-Q, et al. Tumor CTLA-4 overexpression predicts poor survival in patients with nasopharyngeal carcinoma. Oncotarget. 2016;7(11):13060.

55. Regzedmaa O, Li Y, Li Y, Zhang H, Wang J, Gong H, et al. Prevalence of DLL3, CTLA-4 and MSTN expression in patients with small cell lung cancer. Onco Targets Ther. 2019;12:10043.

56. Small EJ, Tchekmedyian NS, Rini BI, Fong L, Lowy I, Allison JP. A pilot trial of CTLA-4 blockade with human anti-CTLA-4 in patients with hor mone-refractory prostate cancer. Clin Cancer Res. 2007;13(6):1810-5.

57. Santoni G, Amantini C, Morelli MB, Tomassoni D, Santoni M, Marinelli $\mathrm{O}$, et al. High CTLA-4 expression correlates with poor prognosis in thymoma patients. Oncotarget. 2018;9(24):16665

58. Shah KV, Chien AJ, Yee C, Moon RT. CTLA-4 is a direct target of Wnt/B catenin signaling and is expressed in human melanoma tumors. $J$ Investig Dermatol. 2008;128(12):2870-9.

59. Pistillo MP, Carosio R, Grillo F, Fontana V, Mastracci L, Morabito A, et al. Phenotypic characterization of tumor CTLA-4 expression in melanoma tissues and its possible role in clinical response to Ipilimumab. Clin Immunol. 2020;215:108428.
60. Omura Y, Toiyama Y, Okugawa Y, Yin C, Shigemori T, Kusunoki K, et al. Prognostic impacts of tumoral expression and serum levels of PD-L1 and CTLA-4 in colorectal cancer patients. Cancer Immunol Immunother. 2020;69(12):2533-46.

61. Han M-Z, Wang S, Zhao W-B, Ni S-L, Yang N, Kong Y, et al. Immune checkpoint molecule herpes virus entry mediator is overexpressed and associated with poor prognosis in human glioblastoma. EBioMedicine. 2019;43:159-70

62. Wang S-D, Li H-Y, Li B-H, Xie T, Zhu T, Sun L-L, et al. The role of CTLA-4 and PD-1 in anti-tumor immune response and their potential efficacy against osteosarcoma. Int Immunopharmacol. 2016;38:81-9.

63. Kythreotou A, Siddique A, Mauri FA, Bower M, Pinato DJ. PD-L1. J Clin Pathol. 2018;71(3):189-94.

64. Iwai Y, Ishida M, Tanaka Y, Okazaki T, Honjo T, Minato N. Involvement of PD-L1 on tumor cells in the escape from host immune system and tumor immunotherapy by PD-L1 blockade. Proc Natl Acad Sci. 2002;99(19):12293-7.

65. Patsoukis N, Duke-Cohan JS, Chaudhri A, Aksoylar H-I, Wang Q Council A, et al. Interaction of SHP-2 SH2 domains with PD-1 ITSM induces PD-1 dimerization and SHP-2 activation. Commun Biol. 2020:3(1):1-13.

66. Veluswamy P, Wacker M, Scherner M, Wippermann J. Delicate role of PD-L1/PD-1 axis in blood vessel inflammatory diseases: current insight and future significance. Int J Mol Sci. 2020;21(21):8159.

67. Taube JM, Klein A, Brahmer JR, Xu H, Pan X, Kim JH, et al. Association of PD-1, PD-1 ligands, and other features of the tumor immune microenvironment with response to anti-PD-1 therapy. Clin Cancer Res. 2014;20(19):5064-74.

68. Hudson K, Cross N, Jordan-Mahy N, Leyland R. The extrinsic and intrinsic roles of PD-L1 and its receptor PD-1: implications for immunotherapy treatment. Front Immunol. 2020;11:2362.

69. Motzer RJ, Tannir NM, McDermott DF, Frontera OA, Melichar B, Choueiri TK, et al. Nivolumab plus ipilimumab versus sunitinib in advanced renal-cell carcinoma. N Engl J Med. 2018.

70. Overman MJ, Lonardi S, Wong KYM, Lenz H-J, Gelsomino F, Aglietta M, et al. Durable clinical benefit with nivolumab plus ipilimumab in DNA mismatch repair-deficient/microsatellite instability-high metastatic colorectal cancer. 2018

71. Yau T, Kang Y-K, Kim T-Y, El-Khoueiry AB, Santoro A, Sangro B, et al. Efficacy and safety of nivolumab plus ipilimumab in patients with advanced hepatocellular carcinoma previously treated with sorafenib: the CheckMate 040 randomized clinical trial. JAMA Oncol. 2020;6(11):e204564

72. Hellmann MD, Paz-Ares L, Bernabe Caro R, Zurawski B, Kim S-W, Carcereny Costa $\mathrm{E}$, et al. Nivolumab plus ipilimumab in advanced non-smallcell lung cancer. N Engl J Med. 2019;381(21):2020-31.

73. Scherpereel A, Mazieres J, Greillier L, Lantuejoul S, Dô P, Bylicki O, et al. Nivolumab or nivolumab plus ipilimumab in patients with relapsed malignant pleural mesothelioma (IFCT-1501 MAPS2): a multicentre, open-label, randomised, non-comparative, phase 2 trial. Lancet Oncol. 2019;20(2):239-53.

74. Lutzky J, Wolchok J, Hamid O, Lebbe C, Pehamberger H, Linette G, et al. Association between immune-related adverse events (irAEs) and disease control or overall survival in patients (pts) with advanced melanoma treated with $10 \mathrm{mg} / \mathrm{kg}$ ipilimumab in three phase II clinical trials. J Clin Oncol. 2009:27(15):9034.

75. Wolchok JD, Weber JS, Maio M, Neyns B, Harmankaya K, Chin K, et al. Four-year survival rates for patients with metastatic melanoma who received ipilimumab in phase II clinical trials. Ann Oncol. 2013;24(8):2174-80

76. Wolchok JD, Chiarion-Sileni V, Gonzalez R, Rutkowski P, Grob J-J, Cowey $\mathrm{CL}$, et al. Overall survival with combined nivolumab and ipilimumab in advanced melanoma. N Engl J Med. 2017:377(14):1345-56.

77. Mankor JM, Disselhorst MJ, Poncin M, Baas P, Aerts JG, Vroman H. Efficacy of nivolumab and ipilimumab in patients with malignant pleural mesothelioma is related to a subtype of effector memory cytotoxic T cells: translational evidence from two clinical trials. EBioMedicine. 2020;62:103040

78. Morse MA, Overman MJ, Hartman L, KhoukazT, Brutcher E, Lenz HJ, et al. Safety of nivolumab plus low-dose ipilimumab in previously treated microsatellite instability-high/mismatch repair-deficient metastatic colorectal cancer. Oncologist. 2019;24(11):1453. 
79. Twomey JD, Zhang B. Cancer immunotherapy update: FDAapproved checkpoint inhibitors and companion diagnostics. AAPS J. 2021;23(2):39

80. Darvin P,Toor SM, Sasidharan Nair V, Elkord E. Immune checkpoint inhibitors: recent progress and potential biomarkers. Exp Mol Med. 2018;50(12):1-11.

81. Pai-Scherf L, Blumenthal GM, Li H, Subramaniam S, Mishra-Kalyani PS, He K, et al. FDA approval summary: pembrolizumab for treatment of metastatic non-small cell lung cancer: first-line therapy and beyond. Oncologist. 2017;22(11):1392-9.

82. Aragon-Ching JB. Pembrolizumab use in bladder cancer: a tale of two trials. Nat Rev Urol. 2021

83. US F. FDA approves pembrolizumab for first-line treatment of head and neck squamous cell carcinoma.

84. Maly J, Alinari L. Pembrolizumab in classical Hodgkin's lymphoma. Eur J Haematol. 2016;97(3):219-27.

85. Yamamoto S, Kato K. Pembrolizumab for the treatment of esophageal cancer. Expert Opin Biol Ther. 2020;20(10):1143-50.

86. Migden MR, Rischin D, Schmults CD, Guminski A, Hauschild A, Lewis KD, et al. PD-1 blockade with cemiplimab in advanced cutaneous squamous-cell carcinoma. N Engl J Med. 2018;379(4):341-51.

87. Larkin J, Lao CD, Urba WJ, McDermott DF, Horak C, Jiang J, et al. Efficacy and safety of nivolumab in patients with BRAF V600 mutant and BRAF wild-type advanced melanoma: a pooled analysis of 4 clinical trials. JAMA Oncol. 2015;1 (4):433-40.

88. Puzanov I, Ribas A, Robert C, Schachter J, Nyakas M, Daud A, et al. Association of BRAF V600E/K mutation status and prior BRAF/MEK inhibition with pembrolizumab outcomes in advanced melanoma: pooled analysis of 3 clinical trials. JAMA Oncol. 2020;6(8):1256-64

89. Huang J, Zhang Y, Sheng J, Zhang H, Fang W, Zhan J, et al. The efficacy and safety of nivolumab in previously treated advanced non-small-cell lung cancer: a meta-analysis of prospective clinical trials. Onco Targets Ther. 2016:9:5867.

90. Horn L, Spigel DR, Vokes EE, Holgado E, Ready N, Steins M, et al. Nivolumab versus docetaxel in previously treated patients with advanced non-small-cell lung cancer: two-year outcomes from two randomized, open-label, phase III trials (CheckMate 017 and CheckMate 057). J Clin Oncol. 2017:35(35):3924.

91. Shaverdian N, Lisberg AE, Bornazyan K, Veruttipong D, Goldman JW, Formenti SC, et al. Previous radiotherapy and the clinical activity and toxicity of pembrolizumab in the treatment of non-small-cell lung cancer: a secondary analysis of the KEYNOTE-001 phase 1 trial. Lancet Oncol. 2017;18(7):895-903.

92. Sundahl N, Rottey S, De Maeseneer D, Ost P. Pembrolizumab for the treatment of bladder cancer. Expert Rev Anticancer Ther. 2018:18(2):107-14.

93. Balar AV, Castellano DE, O'Donnell PH, Grivas P, Vuky J, Powles T, et al. Pembrolizumab as first-line therapy in cisplatin-ineligible advanced urothelial cancer: results from the total KEYNOTE-052 study population. Am Soc Clin Oncol; 2017.

94. Cohen $\mathrm{E}$, Harrington $\mathrm{K}$, Le Tourneau C, Dinis J, Licitra L, Ahn M, et al. Pembrolizumab (pembro) vs standard of care (SOC) for recurrent or metastatic head and neck squamous cell carcinoma (R/M HNSCC): phase 3 KEYNOTE-040 trial. Ann Oncol. 2017;28:628.

95. Rischin D, Harrington KJ, Greil R, Soulieres D, Tahara M, de Castro G, et al. Protocol-specified final analysis of the phase 3 KEYNOTE-048 trial of pembrolizumab (pembro) as first-line therapy for recurrent/metastatic head and neck squamous cell carcinoma (R/M HNSCC). Am Soc Clin Oncol; 2019.

96. Chen R, Zinzani PL, Lee HJ, Armand P, Johnson NA, Brice P, et al. Pembrolizumab in relapsed or refractory Hodgkin lymphoma: 2-year followup of KEYNOTE-087. Blood, J Am Soc Hematol. 2019;134(14):1144-53.

97. Migden MR, Khushalani NI, Chang ALS, Lewis KD, Schmults CD, Hernandez-Aya L, et al. Cemiplimab in locally advanced cutaneous squamous cell carcinoma: results from an open-label, phase 2, single-arm trial. Lancet Oncol. 2020;21(2):294-305.

98. Chang ALS, Lewis KD, Schmults CD, Hernandez-Aya L, Guminski A, Wong DJ, et al. Cemiplimab in locally advanced cutaneous squamous cell carcinoma: results from an open-label, phase 2, single-arm trial. 2020 .
99. Rischin D, Migden MR, Lim AM, Schmults CD, Khushalani NI, Hughes $B G$, et al. Phase 2 study of cemiplimab in patients with metastatic cutaneous squamous cell carcinoma: primary analysis of fixed-dosing, long-term outcome of weight-based dosing. J Immunother Cancer. 2020;8(1).

100. Keeping S, Xu Y, Chen C-I, Cope S, Mojebi A, Kuznik A, et al. Comparative efficacy of cemiplimab versus other systemic treatments for advanced cutaneous squamous cell carcinoma. Future Oncol. 2021;17(5):611-27.

101. Sezer A, Kilickap S, Gümüş M, Bondarenko I, Özgüroğlu M, Gogishvili $M$, et al. Cemiplimab monotherapy for first-line treatment of advanced non-small-cell lung cancer with PD-L1 of at least 50\%: a multicentre, open-label, global, phase 3, randomised, controlled trial. The Lancet. 2021;397(10274):592-604.

102. Philips GK, Atkins M. Therapeutic uses of anti-PD-1 and anti-PD-L1 antibodies. Int Immunol. 2015;27(1):39-46.

103. Balar AV, Galsky MD, Rosenberg JE, Powles T, Petrylak DP, Bellmunt J, et al. Atezolizumab as first-line treatment in cisplatin-ineligible patients with locally advanced and metastatic urothelial carcinoma: a singlearm, multicentre, phase 2 trial. The Lancet. 2017;389(10064):67-76.

104. Socinski MA, Jotte RM, Cappuzzo F, Orlandi F, Stroyakovskiy D, Nogami $\mathrm{N}$, et al. Atezolizumab for first-line treatment of metastatic nonsquamous NSCLC. N Engl J Med. 2018;378(24):2288-301.

105. Casak SJ, Donoghue M, Fashoyin-Aje L, Jiang X, Rodriguez L, Shen Y-L, et al. FDA approval summary: atezolizumab plus bevacizumab for the treatment of patients with advanced unresectable or metastatic hepatocellular carcinoma. Clin Cancer Res. 2021;27(7):1836-41.

106. Gutzmer R, Stroyakovskiy D, Gogas H, Robert C, Lewis K, Protsenko S, et al. Atezolizumab, vemurafenib, and cobimetinib as first-line treatment for unresectable advanced BRAFV600 mutation-positive melanoma (IMspire150): primary analysis of the randomised, double-blind, placebo-controlled, phase 3 trial. The Lancet. 2020;395(10240):1835-44.

107. Syed YY. Durvalumab: first global approval. Drugs. 2017;77(12):1369-76.

108. Baker M, Cordes L, Brownell I. Avelumab: a new standard for treating metastatic Merkel cell carcinoma. Expert Rev Anticancer Ther. 2018;18(4):319-26.

109. Paz-Ares L, Dvorkin M, Chen Y, Reinmuth N, Hotta K, Trukhin D, et al. Durvalumab plus platinum-etoposide versus platinum-etoposide in first-line treatment of extensive-stage small-cell lung cancer (CASPIAN): a randomised, controlled, open-label, phase 3 trial. The Lancet. 2019:394(10212):1929-39.

110. Powles T, Park SH, Voog E, Caserta C, Valderrama BP, Gurney H, et al. Avelumab maintenance therapy for advanced or metastatic urothelial carcinoma. N Engl J Med. 2020;383(13):1218-30.

111. Choueiri TK, Larkin J, Oya M, Thistlethwaite F, Martignoni M, Nathan P, et al. Preliminary results for avelumab plus axitinib as first-line therapy in patients with advanced clear-cell renal-cell carcinoma (JAVELIN Rena 100): an open-label, dose-finding and dose-expansion, phase $1 \mathrm{~b}$ trial. Lancet Oncol. 2018;19(4):451-60.

112. Galsky MD, Arija JÁA, Bamias A, Davis ID, De Santis M, Kikuchi E, et al. Atezolizumab with or without chemotherapy in metastatic urothelial cancer (IMvigor130): a multicentre, randomised, placebo-controlled phase 3 trial. The Lancet. 2020;395(10236):1547-57.

113. Mazieres J, Rittmeyer A, Gadgeel S, Hida T, Gandara DR, Cortinovis DL, et al. Atezolizumab versus docetaxel in pretreated patients with NSCLC: final results from the randomized phase 2 POPLAR and phase 3 OAK clinical trials. J Thorac Oncol. 2021;16(1):140-50.

114. West H, McCleod M, Hussein M, Morabito A, Rittmeyer A, Conter HJ, et al. Atezolizumab in combination with carboplatin plus nab-paclitaxel chemotherapy compared with chemotherapy alone as first-line treatment for metastatic non-squamous non-small-cell lung cancer (IMpower130): a multicentre, randomised, open-label, phase 3 trial. Lancet Oncol. 2019;20(7):924-37.

115. Powles T, O'Donnell PH, Massard C, Arkenau H-T, Friedlander TW, Hoimes CJ, et al. Efficacy and safety of durvalumab in locally advanced or metastatic urothelial carcinoma: updated results from a phase 1/2 open-label study. JAMA Oncol. 2017;3(9):e172411.

116. Kaufman HL, Russell JS, Hamid O, Bhatia S, Terheyden P, D'Angelo SP, et al. Updated efficacy of avelumab in patients with previously treated metastatic Merkel cell carcinoma after $\geq 1$ year of follow-up: JAVELIN Merkel 200, a phase 2 clinical trial. J Immunother Cancer. 2018;6(1):1-7. 
117. D'Angelo SP, Bhatia S, Brohl AS, Hamid O, Mehnert JM, Terheyden P, et al. Avelumab in patients with previously treated metastatic Merkel cell carcinoma: long-term data and biomarker analyses from the single-arm phase 2 JAVELIN Merkel 200 trial. J Immunother Cancer. 2020;8(1).

118. Larkin JM, Gordon MS, Thistlethwaite F, Nathan PD, Rini BI, Martignon M, et al. Avelumab (MSB0010718C; anti-PD-L1) in combination with axitinib as first-line treatment for patients with advanced renal cell carcinoma. Am Soc Clin Oncol; 2016

119. Motzer RJ, Robbins PB, Powles T, Albiges L, Haanen JB, Larkin J, et al. Avelumab plus axitinib versus sunitinib in advanced renal cell carcinoma: biomarker analysis of the phase 3 JAVELIN Renal 101 trial. Nat Med. 2020;26(11):1733-41.

120. Laplane L, Duluc D, Larmonier N, Pradeu T, Bikfalvi A. The multiple layers of the tumor environment. Trends Cancer. 2018:4(12):802-9.

121. Tang H, Qiao J, Fu Y-X. Immunotherapy and tumor microenvironment. Cancer Lett. 2016;370(1):85-90.

122. Yoo SY, Badrinath N, Jeong S-N, Woo HY, Heo J. Overcoming tumor resistance to oncolyticvaccinia virus with anti-PD-1-based combination therapy by inducing antitumor immunity in the tumor microenvironment. Vaccines. 2020;8(2):321.

123. Zhang Y, Ertl HC. Starved and asphyxiated: how can CD8+ T cells within a tumor microenvironment prevent tumor progression. Front Immunol. 2016;7:32.

124. Jiang Y, Zhan H. Communication between EMT and PD-L1 signaling: new insights into tumor immune evasion. Cancer Lett. 2020;468:72-81.

125. Lucibello G, Mograbi B, Milano G, Hofman P, Brest P. PD-L1 regulation revisited: impact on immunotherapeutic strategies. Trends Mol Med. 2021

126. Jiang Z, Hsu JL, Li Y, Hortobagyi GN, Hung M-C. Cancer cell metabolism bolsters immunotherapy resistance by promoting an immunosuppressive tumor microenvironment. Front Oncol. 2020;10:1197.

127. Kim C, Kim JH, Kim JS, Chon HJ, Kim J-H. A novel dual inhibitor of IDO and TDO, CMG017, potently suppresses the kynurenine pathway and overcomes resistance to immune checkpoint inhibitors. Am Soc Clin Oncol. 2019.

128. Hou A, Hou K, Huang Q, Lei Y, Chen W. Targeting myeloid-derived suppressor cell, a promising strategy to overcome resistance to immune checkpoint inhibitors. Front Immunol. 2020;11:783.

129. O'Donnell JS, Teng MW, Smyth MJ. Cancer immunoediting and resistance to T cell-based immunotherapy. Nat Rev Clin Oncol. 2019;16(3):151-67.

130. Li X, Xiang Y, Li F, Yin C, Li B, Ke X.WNT/ß-catenin signaling pathway regulating $T$ cell-inflammation in the tumor microenvironment. Front immunol. 2019:10:2293.

131. Spranger S, Bao R, Gajewski TF. Melanoma-intrinsic $\beta$-catenin signalling prevents anti-tumour immunity. Nature. 2015;523(7559):231-5.

132. Peng W, Chen JQ, Liu C, Malu S, Creasy C, Tetzlaff MT, et al. Loss of PTEN promotes resistance to T cell-mediated immunotherapy. Cancer Discov. 2016:6(2):202-16.

133. Hutchinson L. Evading immune escape: synergy of COX and immunecheckpoint inhibitors. Nat Rev Clin Oncol. 2015;12(11):622.

134. Pu D, Yin L, Huang L, Qin C, Zhou Y, Wu Q, et al. Cyclooxygenase-2 inhibitor: a potential combination strategy with immunotherapy in cancer. Front Oncol. 2021;11

135. Ma G, Li C, Zhang Z, Liang Y, Liang Z, Chen Y, et al. Targeted glucose or glutamine metabolic therapy combined with PD-1/PD-L1 checkpoint blockade immunotherapy for the treatment of tumors-mechanisms and strategies. Front Oncol. 2021;11:697894.

136. Shin DS, Zaretsky JM, Escuin-Ordinas H, Garcia-Diaz A, Hu-Lieskovan S, Kalbasi A, et al. Primary resistance to PD-1 blockade mediated by JAK1/2 mutations. Cancer Discov. 2017;7(2):188-201.

137. Reck M, Liu SV, Mansfield AS, MokT, Scherpereel A, Reinmuth $\mathrm{N}$, et al. IMpower133: updated overall survival (OS) analysis of first-line (1L) atezolizumab (atezo) + carboplatin + etoposide in extensive-stage SCLC (ES-SCLC). Ann Oncol. 2019;30:v710-1.

138. Mathieu L, Shah S, Pai-Scherf L, Larkins E, Vallejo J, Li X, et al. FDA approval summary: atezolizumab and durvalumab in combination with platinum-based chemotherapy in extensive stage small cell lung cancer. Oncologist. 2021;26(5):433-8.

139. Socinski MA, Nishio M, Jotte RM, Cappuzzo F, Orlandi F, Stroyakovskiy D, et al. IMpower150 final overall survival analyses for atezolizumab plus bevacizumab and chemotherapy in first-line metastatic nonsquamous NSCLC. J Thorac Oncol. 2021;16(11):1909-24

140. Falvo P, Orecchioni S, Hillje R, Raveane A, Mancuso P, Camisaschi C, et al. Cyclophosphamide and vinorelbine activate stem-like CD8(+) T cells and improve anti-PD-1 efficacy in triple-negative breast cancer. Cancer Res. 2021;81(3):685-97.

141. Orecchioni S, Talarico G, Labanca V Calleri A, Mancuso P, Bertolini F. Vinorelbine, cyclophosphamide and 5-FU effects on the circulating and intratumoural landscape of immune cells improve anti-PD-L1 efficacy in preclinical models of breast cancer and lymphoma. Br J Cancer. 2018;118(10):1329-36.

142. Parra K, Valenzuela P, Lerma N, Gallegos A, Reza LC, Rodriguez G, et al. Impact of CTLA-4 blockade in conjunction with metronomic chemotherapy on preclinical breast cancer growth. Br J Cancer. 2017; 116(3):324-34

143. Babiker H, Brana I, Mahadevan D, Owonikoko T, Calvo E, Rischin D, et al. Phase I trial of cemiplimab, radiotherapy, cyclophosphamide, and granulocyte macrophage colony-stimulating factor in patients with recurrent or metastatic head and neck squamous cell carcinoma. Oncologist. 2021;26(9):e1508-13.

144. Salewski I, Henne J, Engster L, Schneider B, Lemcke H, Skorska A, et al. Combined gemcitabine and immune-checkpoint inhibition conquers anti-PD-L1 resistance in low-immunogenic mismatch repair-deficient tumors. Int J Mol Sci. 2021;22(11):5990.

145. Sen T, Della Corte CM, Milutinovic S, Cardnell RJ, Diao L, Ramkumar K, et al. Combination treatment of the oral CHK1 inhibitor, SRA737, and low-dose gemcitabine enhances the effect of programmed death ligand 1 blockade by modulating the immune microenvironment in SCLC. J Thorac Oncol. 2019:14(12):2152-63.

146. Du B, Wen X, Wang Y, Lin M, Lai J. Gemcitabine and checkpoint blockade exhibit synergistic anti-tumor effects in a model of murine lung carcinoma. Int Immunopharmacol. 2020;86:106694.

147. Tallón de Lara P, Cecconi V, Hiltbrunner S, Yagita H, Friess M, Bode B, et al. Gemcitabine synergizes with immune checkpoint inhibitors and overcomes resistance in a preclinical model and mesothelioma patients. Clin Cancer Res. 2018;24(24):6345-54.

148. Ueno M, Ikeda M, Morizane C, Kobayashi S, Ohno I, Kondo S, et al. Nivolumab alone or in combination with cisplatin plus gemcitabine in Japanese patients with unresectable or recurrent biliary tract cancer: a non-randomised, multicentre, open-label, phase 1 study. Lancet Gastroenterol Hepatol. 2019;4(8):611-21.

149. Feng K, Liu Y, Zhao Y, Yang Q, Dong L, Liu J, et al. Efficacy and biomarker analysis of nivolumab plus gemcitabine and cisplatin in patients with unresectable or metastatic biliary tract cancers: results from a phase II study. J Immunother Cancer. 2020;8(1):000367.

150. Sun F, Cui L, LiT, Chen S, Song J, Li D. Oxaliplatin induces immunogenic cells death and enhances therapeutic efficacy of checkpoint inhibitor in a model of murine lung carcinoma. J Recept Signal Transduct Res. 2019:39(3):208-14

151. Fu D, Wu J, Lai J, Liu Y, Zhou L, Chen L, et al. T cell recruitment triggered by optimal dose platinum compounds contributes to the therapeutic efficacy of sequential PD-1 blockade in a mouse model of colon cancer. Am J Cancer Res. 2020:10(2):473-90.

152. Fournel L, Wu Z, Stadler N, Damotte D, Lococo F, Boulle G, et al. Cisplatin increases PD-L1 expression and optimizes immune check-point blockade in non-small cell lung cancer. Cancer Lett. 2019;464:5-14.

153. Voorwerk L, Slagter M, Horlings HM, Sikorska K, van de Vijver KK, de Maaker $\mathrm{M}$, et al. Immune induction strategies in metastatic triplenegative breast cancer to enhance the sensitivity to PD-1 blockade: the TONIC trial. Nat Med. 2019;25(6):920-8.

154. Chen Q, Xia R, Zheng W, Zhang L, Li P, Sun X, et al. Metronomic paclitaxel improves the efficacy of PD-1 monoclonal antibodies in breast cancer by transforming the tumor immune microenvironment. Am J Transl Res. 2020;12(2):519-30.

155. Feng B, Niu Z, Hou B, Zhou L, Li Y, Yu H. Enhancing triple negative breast cancer immunotherapy by ICG-templated self-assembly of paclitaxel nanoparticles. Adv Func Mater. 2020;30(6):1906605.

156. Yang $Q$, Shi G, Chen X, Lin Y, Cheng L, Jiang Q, et al. Nanomicelle protects the immune activation effects of Paclitaxel and sensitizes tumors to anti-PD-1 Immunotherapy. Theranostics. 2020;10(18):8382-99. 
157. Li JJ, Wang JH, Dingv Y, Li DD, Wen XZ, Zhao JJ, et al. Efficacy and safety of anti-PD-1 inhibitor combined with nab-paclitaxel in Chinese patients with refractory melanoma. J Cancer Res Clin Oncol. 2021.

158. Zhang F, Huang D, Zhao L, Li T, Zhang S, Zhang G, et al. Efficacy and safety of PD-1/PD-L1 inhibitors plus nab-paclitaxel for patients with non-small cell lung cancer who have progressed after platinum-based chemotherapy. Ther Adv Med Oncol. 2020;12:1758835920936882.

159. Lee EK, Xiong N, Cheng SC, Barry WT, Penson RT, Konstantinopoulos PA, et al. Combined pembrolizumab and pegylated liposomal doxorubicin in platinum resistant ovarian cancer: a phase 2 clinical trial. Gynecol Oncol. 2020;159(1):72-8.

160. Rubin I, Yarden Y. The basic biology of HER2. Ann Oncol. 2001;12:S3-8.

161. Iwata TN, Ishii C, Ishida S, Ogitani Y, Wada T, Agatsuma T. A HER2-targeting antibody-drug conjugate, trastuzumab deruxtecan (DS-8201a), enhances antitumor immunity in a mouse model. Mol Cancer Ther. 2018;17(7):1494-503.

162. Iwata TN, Sugihara K, Wada T, Agatsuma T. [Fam-] trastuzumab deruxtecan (DS-8201a)-induced antitumor immunity is facilitated by the antiCTLA-4 antibody in a mouse model. PLoS ONE. 2019;14(10):e0222280.

163. Müller P, Kreuzaler M, Khan T, Thommen DS, Martin K, Glatz K, et al. Trastuzumab emtansine (T-DM1) renders HER2+ breast cancer highly susceptible to CTLA-4/PD-1 blockade. Sci Transl Med. 2015;7(315):315ra188

164. D’Amico L, Menzel U, Prummer M, Müller P, Buchi M, Kashyap A, et al. A novel anti-HER2 anthracycline-based antibody-drug conjugate induces adaptive anti-tumor immunity and potentiates PD-1 blockade in breast cancer. J Immunother Cancer. 2019:7(1):16.

165. Catenacci DVT, Kang YK, Park H, Uronis HE, Lee KW, Ng MCH, et al. Margetuximab plus pembrolizumab in patients with previously treated, HER2-positive gastro-oesophageal adenocarcinoma (CP-MGAH22-05): a single-arm, phase 1b-2 trial. Lancet Oncol. 2020;21(8):1066-76.

166. Tian X, Zhu Q, Zhang Z. Durable clinical response to immune and targeted therapies in an elderly man with synchronous gastric (HER2+) and bladder cancers: case report and literature review. Onco Targets Ther. 2021;14:3701-8.

167. Jubb AM, Oates AJ, Holden S, Koeppen H. Predicting benefit from antiangiogenic agents in malignancy. Nat Rev Cancer. 2006;6(8):626-35

168. Wilky BA, Trucco MM, Subhawong TK, Florou V, Park W, Kwon D, et al. Axitinib plus pembrolizumab in patients with advanced sarcomas including alveolar soft-part sarcoma: a single-centre, single-arm, phase 2 trial. Lancet Oncol. 2019;20(6):837-48.

169. Al-Abd AM, Alamoudi AJ, Abdel-Naim AB, Neamatallah TA, Ashour OM. Anti-angiogenic agents for the treatment of solid tumors: potential pathways, therapy and current strategies-a review. J Adv Res. 2017:8(6):591-605.

170. Mukherii S. Bevacizumab (avastin). Am J Neuroradiol. 2010;31(2):235-6.

171. Reck M, Shankar G, Lee A, Coleman S, McCleland M, Papadimitrakopoulou VA, et al. Atezolizumab in combination with bevacizumab, paclitaxel and carboplatin for the first-line treatment of patients with metastatic non-squamous non-small cell lung cancer, including patients with EGFR mutations. Expert Rev Respir Med. 2020;14(2):125-36.

172. McDermott DF, Huseni MA, Atkins MB, Motzer RJ, Rini BI, Escudier B, et al. Clinical activity and molecular correlates of response to atezolizumab alone or in combination with bevacizumab versus sunitinib in renal cell carcinoma. Nat Med. 2018;24(6):749-57.

173. Liu JF, Herold C, Gray KP, Penson RT, Horowitz N, Konstantinopoulos PA, et al. Assessment of combined nivolumab and bevacizumab in relapsed ovarian cancer: a phase 2 clinical trial. JAMA Oncol. 2019;5(12):1731-8.

174. Kudo M, Motomura K, Wada Y, Inaba Y, Sakamoto Y, Kurosaki M, et al. First-line avelumab+ axitinib in patients with advanced hepatocellular carcinoma: Results from a phase 1b trial (VEGF Liver 100). Am Soc Clin Oncol. 2019;37:4072

175. Fukuoka S, Hara H, Takahashi N, Kojima T, Kawazoe A, Asayama $M$, et al. Regorafenib plus nivolumab in patients with advanced gastric or colorectal cancer: an open-label, dose-escalation, and dose-expansion phase Ib trial (REGONIVO, EPOC1603). J Clin Oncol. 2020;38(18):2053-61.

176. Li J, Cong L, Liu J, Peng L, Wang J, Feng A, et al. The efficacy and safety of regorafenib in combination with anti-PD-1 antibody in refractory microsatellite stable metastatic colorectal cancer: a retrospective study. Front Oncol. 2020;10:2449.

177. Lin P-T, Teng W, Jeng W-J, Lin C-Y, Lin S-M, Sheen I-S. Combining immune checkpoint inhibitor with lenvatinib prolongs survival than lenvatinib alone in sorafenib-experienced hepatocellular carcinoma patients. Eur J Gastroenterol Hepatol. 2020

178. Amin A, Plimack ER, Ernstoff MS, Lewis LD, Bauer TM, McDermott DF, et al. Safety and efficacy of nivolumab in combination with sunitinib or pazopanib in advanced or metastatic renal cell carcinoma: the CheckMate 016 study. J Immunother Cancer. 2018;6(1):1-12.

179. Pardoll DM. Cancer vaccines. Nat Med. 1998:4(5):525-31.

180. Finn OJ. Cancer vaccines: between the idea and the reality. Nat Rev Immunol. 2003;3(8):630-41.

181. Gatti-Mays ME, Redman JM, Collins JM, Bilusic M. Cancer vaccines: enhanced immunogenic modulation through therapeutic combinations. Hum Vaccin Immunother. 2017:13(11):2561-74.

182. Ferrucci PF, Pala L, Conforti F, Cocorocchio E. Talimogene laherparepvec (T-VEC): an intralesional cancer immunotherapy for advanced melanoma. Cancers. 2021;13(6):1383.

183. Anassi E, Ndefo UA. Sipuleucel-T (provenge) injection: the first immunotherapy agent (vaccine) for hormone-refractory prostate cancer. P \& T. 2011;36(4):197-202

184. Guallar-Garrido S, Julián E. Bacillus Calmette-Guérin (BCG) therapy for bladder cancer: an update. ImmunoTargets Ther. 2020;9:1-11.

185. Zheng F, Dang J, Zhang H, Xu F, Ba D, Zhang B, et al. Cancer stem cell vaccination with PD-L1 and CTLA-4 blockades enhances the eradication of melanoma stem cells in a mouse tumor model. J immunother. 2018;41(8):361

186. Hurwitz AA, Foster BA, Kwon ED, Truong T, Choi EM, Greenberg $\mathrm{NM}$, et al. Combination immunotherapy of primary prostate cancer in a transgenic mouse model using CTLA-4 blockade. Can Res. 2000;60(9):2444-8.

187. Soares KC, Rucki AA, Wu AA, Olino K, Xiao Q, Chai Y, et al. PD-1/PD-L1 blockade together with vaccine therapy facilitates effector $T$ cell infiltration into pancreatic tumors. J Immunother. 2015;38(1):1.

188. Antonios JP, Soto H, Everson RG, Orpilla J, Moughon D, Shin N, et al. PD-1 blockade enhances the vaccination-induced immune response in glioma. JCI Insight. 2016;1(10).

189. Kadam P, Sharma S. PD-1 immune checkpoint blockade promotes therapeutic cancer vaccine to eradicate lung cancer. Vaccines. 2020;8(2):317

190. Fu J, Malm I-J, Kadayakkara DK, Levitsky H, Pardoll D, Kim YJ. Preclinical evidence that PD1 blockade cooperates with cancer vaccine TEGVAX to elicit regression of established tumors. Can Res. 2014;74(15):4042-52.

191. Lopes A, Vanvarenberg K, Kos Š, Lucas S, Colau D, Van den Eynde B, et al Combination of immune checkpoint blockade with DNA cancer vaccine induces potent antitumor immunity against P815 mastocytoma. Sci Rep. 2018;8(1):1-11.

192. Hwang HS, Cherukula K, Bang YJ, Vijayan V, Moon MJ, Thiruppathi J, et al. Combination of photodynamic therapy and a flagellin-adjuvanted cancer vaccine potentiated the anti-PD-1-mediated melanoma suppression. Cells. 2020;9(11):2432.

193. Yang $\mathrm{P}$, Song H, Oin Y, Huang $\mathrm{P}$, Zhang C, Kong D, et al. Engineering dendritic-cell-based vaccines and PD-1 blockade in self-assembled peptide nanofibrous hydrogel to amplify antitumor T-cell immunity. Nano Lett. 2018;18(7):4377-85.

194. Singh M, Vianden C, Cantwell MJ, Dai Z, Xiao Z, Sharma M, et al. Intratumoral CD40 activation and checkpoint blockade induces T cell-mediated eradication of melanoma in the brain. Nat Commun. 2017:8(1):1-10.

195. Sivanandam V, LaRocca CJ, Chen NG, Fong Y, Warner SG. Oncolytic viruses and immune checkpoint inhibition: the best of both worlds. Mol Therapy-Oncolytics. 2019;13:93-106.

196. Woller N, Gürlevik E, Fleischmann-Mundt B, Schumacher A, Knocke $\mathrm{S}$, Kloos AM, et al. Viral infection of tumors overcomes resistance to PD-1-immunotherapy by broadening neoantigenome-directed T-cell responses. Mol Ther. 2015;23(10):1630-40.

197. Hardcastle J, Mills L, Malo CS, Jin F, Kurokawa C, Geekiyanage H, et al. Immunovirotherapy with measles virus strains in combination with anti-PD-1 antibody blockade enhances antitumor activity in glioblastoma treatment Neuro Oncol. 2017:19(4):493-502. 
198. Saha D, Martuza RL, Rabkin SD. Oncolytic herpes simplex virus immunovirotherapy in combination with immune checkpoint blockade to treat glioblastoma. Immunotherapy. 2018;10(9):779-86.

199. De Keersmaecker B, Claerhout S, Carrasco J, Bar I, Corthals J, Wilgenhof S, et al. TriMix and tumor antigen mRNA electroporated dendritic cell vaccination plus ipilimumab: link between T-cell activation and clinical responses in advanced melanoma. J Immunother Cancer. 2020;8(1):000329.

200. Le DT, Lutz E, Uram JN, Sugar EA, Onners B, Solt S, et al. Evaluation of ipilimumab in combination with allogeneic pancreatic tumor cells transfected with a GM-CSF gene in previously treated pancreatic cancer. J Immunother. 2013;36(7):382-9.

201. Massarelli E, William W, Johnson F, Kies M, Ferrarotto R, Guo M, et al. Combining immune checkpoint blockade and tumor-specific vaccine for patients with incurable human papillomavirus 16-related cancer: a phase 2 clinical trial. JAMA Oncol. 2019;5(1):67-73.

202. Grass GD, Krishna N, Kim S. The immune mechanisms of abscopal effect in radiation therapy. Curr Probl Cancer. 2016;40(1):10-24.

203. Brix N, Tiefenthaller A, Anders H, Belka C, Lauber K. Abscopal, immunological effects of radiotherapy: narrowing the gap between clinical and preclinical experiences. Immunol Rev. 2017;280(1):249-79.

204. Stessin AM, Clausi MG, Zhao Z, Lin H, Hou W, Jiang Z, et al. Repolarized macrophages, induced by intermediate stereotactic dose radiotherapy and immune checkpoint blockade, contribute to long-term survival in glioma-bearing mice. J Neurooncol. 2020;147(3):547-55.

205. Wang F, Luo Y, Tian X, Ma S, Sun Y, You C, et al. Impact of radiotherapy concurrent with anti-PD-1 therapy on the lung tissue of tumor-bearing mice. Radiat Res. 2019;191(3):271-7.

206. Helm A, Tinganelli W, Simoniello P, Kurosawa F, Fournier C, Shimokawa $T$, et al. Reduction of lung metastases in a mouse osteosarcoma model treated with carbon ions and immune checkpoint inhibitors. Int J Radiat Oncol Biol Phys. 2021;109(2):594-602.

207. Dudzinski SO, Cameron BD, Wang J, Rathmell JC, Giorgio TD, Kirschner AN. Combination immunotherapy and radiotherapy causes an abscopal treatment response in a mouse model of castration resistant prostate cancer. J Immunother Cancer. 2019;7(1):1-8.

208. Yamaguchi O, Kaira K, Hashimoto K, Mouri A, Miura Y, Shiono A, et al. Radiotherapy is an independent prognostic marker of favorable prognosis in non-small cell lung cancer patients after treatment with the immune checkpoint inhibitor, nivolumab. Thoracic Cancer. 2019;10(4):992-1000.

209. Schubert P, Rutzner S, Eckstein M, Frey B, Schweizer C, Haderlein M, et al. Prospective evaluation of all-lesion versus single-lesion radiotherapy in combination with PD-1/PD-L1 immune checkpoint inhibitors. Front Oncol. 2020;10.

210. Xu Z, Feng J, Weng $Y$, Jin $Y$, Peng M. Combination of immune checkpoint inhibitors and radiotherapy for advanced non-small-cell lung cancer and prostate cancer: a meta-analysis. J Oncol. 2021;2021:6631643.

211. Mohamad O, Diaz de Leon A, Schroeder S, Leiker A, Christie A, ZhangVelten $E$, et al. Safety and efficacy of concurrent immune checkpoint inhibitors and hypofractionated body radiotherapy. Oncoimmunology. 2018;7(7):e1440168.

212. Bang A, Wilhite TJ, Pike LRG, Cagney DN, Aizer AA, Taylor A, et al. Multicenter evaluation of the tolerability of combined treatment with PD-1 and CTLA-4 immune checkpoint inhibitors and palliative radiation therapy. Int J Radiat Oncol Biol Phys. 2017;98(2):344-51.

213. Xie C, Duffy AG, Brar G, Fioravanti S, Mabry-Hrones D, Walker M, et al. Immune checkpoint blockade in combination with stereotactic body radiotherapy in patients with metastatic pancreatic ductal adenocarcinoma. Clin Cancer Res. 2020;26(10):2318-26.

214. Pike LR, Bang A, Mahal BA, Taylor A, Krishnan M, Spektor A, et al. The impact of radiation therapy on lymphocyte count and survival in metastatic cancer patients receiving PD-1 immune checkpoint inhibitors. Int J Radiat Oncol Biol Phys. 2019;103(1):142-51.

215. Kato D, Yaguchi T, Iwata T, Morii K, Nakagawa T, Nishimura R, et al. Prospects for personalized combination immunotherapy for solid tumors based on adoptive cell therapies and immune checkpoint blockade therapies. Jpn J Clin Immun. 2017:40(1):68-77.

216. Feros DL, Lane L, Ciarrochi J, Blackledge JT. Acceptance and Commitment Therapy (ACT) for improving the lives of cancer patients: a preliminary study. Psychooncology. 2013;22(2):459-64.
217. Kodumudi KN, Siegel J, Weber AM, Scott E, Sarnaik AA, Pilon-Thomas S. Immune checkpoint blockade to improve tumor infiltrating lymphocytes for adoptive cell therapy. PLoS ONE. 2016;11(4):e0153053.

218. Mullinax JE, Hall M, Prabhakaran S, Weber J, Khushalani N, Eroglu Z, et al Combination of ipilimumab and adoptive cell therapy with tumorinfiltrating lymphocytes for patients with metastatic melanoma. Front Oncol. 2018:8:44.

219. Kverneland AH, Pedersen M, Westergaard MCW, Nielsen M, Borch TH, Olsen LR, et al. Adoptive cell therapy in combination with checkpoint inhibitors in ovarian cancer. Oncotarget. 2020;11(22):2092.

220. Rafiq S, Yeku OO, Jackson HJ, Purdon TJ, van Leeuwen DG, Drakes DJ, et al. Targeted delivery of a PD-1-blocking scFv by CAR-T cells enhances anti-tumor efficacy in vivo. Nat Biotechnol. 2018;36(9):847-56.

221. Shaw AR, Porter CE, Watanabe N, Tanoue K, Sikora A, Gottschalk S, et al. Adenovirotherapy delivering cytokine and checkpoint inhibitor augments CAR T cells against metastatic head and neck cancer. Mol Ther. 2017;25(11):2440-51.

222. Song Y, Liu Q, Zuo T, Wei G, Jiao S. Combined antitumor effects of antiEGFR variant III CAR-T cell therapy and PD-1 checkpoint blockade on glioblastoma in mouse model. Cell Immunol. 2020;352:104112.

223. Adusumilli PS, Zauderer MG, Rivière I, Solomon SB, Rusch VW, O'Cearbhaill RE, et al. A phase I trial of regional mesothelin-targeted CART-cell therapy in patients with malignant pleural disease, in combination with the anti-PD-1 agent pembrolizumab. Cancer Discovery. 2021.

224. Adusumilli PS, Zauderer MG, Rusch VW, O'Cearbhaill R, Zhu A, Ngai D, et al. Regional delivery of mesothelin-targeted CART cells for pleural cancers: safety and preliminary efficacy in combination with anti-PD-1 agent. Am Soc Clin Oncol. 2019;37:2511.

225. Maude SL, Hucks GE, Seif AE, Talekar MK, Teachey DT, Baniewicz D, et al. The effect of pembrolizumab in combination with CD19-targeted chimeric antigen receptor (CAR) T cells in relapsed acute lymphoblastic leukemia (ALL). Am Soc Clin Oncol. 2017;35:103.

226. Wang J, Loberg R, Taichman RS. The pivotal role of CXCL12 (SDF-1)/CXCR4 axis in bone metastasis. Cancer Metastasis Rev. 2006;25(4):573-87.

227. Kryczek I, Wei S, Keller E, Liu R, Zou W. Stroma-derived factor (SDF-1/ CXCL12) and human tumor pathogenesis. Am J Physiol Cell Physiol. 2007;292(3):C987-95.

228. Zhou W, Guo S, Liu M, Burow ME, Wang G. Targeting CXCL12/CXCR4 axis in tumor immunotherapy. Curr Med Chem. 2019;26(17):3026-41.

229. Otsuka S, Bebb G. The CXCR4/SDF-1 chemokine receptor axis: a new target therapeutic for non-small cell lung cancer. J Thorac Oncol. 2008;3(12):1379-83.

230. Schrader A, Lechner O, Templin M, Dittmar K, Machtens S, Mengel M, et al. CXCR4/CXCL12 expression and signalling in kidney cancer. $\mathrm{Br}$ J Cancer. 2002:86(8):1250-6.

231. Chen Y, Ramjiawan RR, Reiberger T, Ng MR, Hato T, Huang Y, et al. CXCR4 inhibition in tumor microenvironment facilitates anti-programmed death receptor-1 immunotherapy in sorafenib-treated hepatocellular carcinoma in mice. Hepatology. 2015;61(5):1591-602.

232. Jiang K, Li J, Zhang J, Wang L, Zhang Q, Ge J, et al. SDF-1/CXCR4 axis facilitates myeloid-derived suppressor cells accumulation in osteosarcoma microenvironment and blunts the response to anti-PD-1 therapy. Int Immunopharmacol. 2019;75:105818.

233. Zeng Y, Li B, Liang Y, Reeves PM, Qu X, Ran C, et al. Dual blockade of CXCL12-CXCR4 and PD-1-PD-L1 pathways prolongs survival of ovarian tumor-bearing mice by prevention of immunosuppression in the tumor microenvironment. FASEB J. 2019;33(5):6596-608.

234. Starbuck K, McGray R, Masoumi-Moghaddam S, Francois A, Odunsi K, Zsiros E. Novel oral small molecule CXCR4 inhibitor improves activity of immune checkpoint blockade in ovarian cancer mouse model. AACR; 2017.

235. Lu G, Oiu Y, Su X. Targeting CXCL12-CXCR4 signaling enhances immune checkpoint blockade therapy against triple negative breast cancer. Eur J Pharm Sci. 2021;157:105606.

236. D'Alterio C, Buoncervello M, leranò C, Napolitano M, Portella L, Rea G, et al. Targeting CXCR4 potentiates anti-PD-1 efficacy modifying the tumor microenvironment and inhibiting neoplastic PD-1. J Exp Clin Cancer Res. 2019:38(1):1-13. 
237. Seo YD, Jiang X, Sullivan KM, Jalikis FG, Smythe KS, Abbasi A, et al. Mobilization of CD8+T cells via CXCR4 blockade facilitates PD-1 checkpoint therapy in human pancreatic cancer. Clin Cancer Res. 2019;25(13):3934-45.

238. Pellicciotta I, Alouani EL, Raufi A, Pan SM, Hu J, Manji GA. Chemo4MetPanc: A phase II study with combination chemotherapy (gemcitabine and nab-paclitaxel), chemokine (CXC) motif receptor 4 inhibitor (motixafortide), and immune checkpoint blockade (cemiplimab) in metastatic treatment naïve pancreas adenocarcinoma (PDAC). Am Soc Clin Oncol; 2021.

239. Choueiri TK, Atkins MB, Rose TL, Alter RS, Ju Y, Niland K, et al. A phase $1 \mathrm{~b}$ trial of the CXCR4 inhibitor mavorixafor and nivolumab in advanced renal cell carcinoma patients with no prior response to nivolumab monotherapy. Invest New Drugs. 2021:1-9.

240. Choueiri T, Atkins M, Rose T, Alter R, Tsiroyannis E, Niland K, et al. A phase la/llb trial of the CXCR4 inhibitor X4P-001 and nivolumab for advanced renal cell carcinoma (RCC) that is unresponsive to nivolumab monotherapy. Ann Oncol. 2018;29:viii402-3.

241. Johnson DB, Reynolds KL, Sullivan RJ, Balko JM, Patrinely JR, Cappelli LC, et al. Immune checkpoint inhibitor toxicities: systems-based approaches to improve patient care and research. Lancet Oncol. 2020;21(8):e398-404.

242. Agarwal K, Yousaf N, Morganstein D. Glucocorticoid use and complications following immune checkpoint inhibitor use in melanoma. Clin Med. 2020;20(2):163.

243. Zhang L, Zlotoff DA, Awadalla M, Mahmood SS, Nohria A, Hassan MZ, et al. Major adverse cardiovascular events and the timing and dose of corticosteroids in immune checkpoint Inhibitor-Associated myocarditis. Circulation. 2020;141(24):2031-4

244. Kang BW, Chau I. Current status and future potential of predictive biomarkers for immune checkpoint inhibitors in gastric cancer. ESMO Open. 2020;5(4):e000791.

245. Raimondi A, Sepe P, Zattarin E, Mennitto A, Stellato M, Claps M, et al. Predictive biomarkers of response to immunotherapy in metastatic renal cell cancer. Front Oncol. 2020;10:1644.

246. Giustini N, Bazhenova L. Recognizing prognostic and predictive biomarkers in the treatment of non-small cell lung cancer (NSCLC) with immune checkpoint inhibitors (ICls). Lung Cancer: Targets Ther. 2021;12:21

247. Miyake M, Hori S, Owari T, Oda Y, Tatsumi Y, Nakai Y, et al. Clinical impact of tumor-infiltrating lymphocytes and PD-L1-positive cells as prognostic and predictive biomarkers in urological malignancies and retroperitoneal sarcoma. Cancers. 2020;12(11):3153.

248. Grasselly C, Denis M, Bourguignon A, Talhi N, Mathe D, Tourette A, et al. The antitumor activity of combinations of cytotoxic chemotherapy and immune checkpoint inhibitors is model-dependent. Front Immunol. 2018:9:2100.

249. Ho TTB, Nasti A, Seki A, Komura T, Inui H, Kozaka T, et al. Combination of gemcitabine and anti-PD-1 antibody enhances the anticancer effect of M1 macrophages and the Th1 response in a murine model of pancreatic cancer liver metastasis. J Immunother Cancer. 2020:8(2):001367.

250. Zheng S, Song D, Jin X, Zhang H, Aldarouish M, Chen Y, et al. Targeted microbubbles with ultrasound irradiation and PD-1 inhibitor to increase antitumor activity in B-cell lymphoma. Nanomedicine (Lond). 2018;13(3):297-311

251. Grabosch S, Bulatovic M, Zeng F, Ma T, Zhang L, Ross M, et al. Cisplatininduced immune modulation in ovarian cancer mouse models with distinct inflammation profiles. Oncogene. 2019;38(13):2380-93.

252. Gao F, Zhang C, Qiu WX, Dong X, Zheng DW, Wu W, et al. PD-1 blockade for improving the antitumor efficiency of polymer-doxorubicin nanoprodrug. Small. 2018;14(37):e1802403.

253. Lévesque S, Le Naour J, Pietrocola F, Paillet J, Kremer M, Castoldi F, et al. A synergistic triad of chemotherapy, immune checkpoint inhibitors, and caloric restriction mimetics eradicates tumors in mice. Oncoimmunology. 2019;8(11):e1657375.

254. Saha D, Martuza RL, Rabkin SD. Macrophage polarization contributes to glioblastoma eradication by combination immunovirotherapy and immune checkpoint blockade. Cancer Cell. 2017;32(2):253-67.e5.

255. Ali OA, Lewin SA, Dranoff G, Mooney DJ. Vaccines combined with immune checkpoint antibodies promote cytotoxic T-cell activity and tumor eradication. Cancer Immunol Res. 2016:4(2):95-100.
256. Kanaya N Kuroda S, Kakiuchi Y Kumon K Tsumura T, Hashimoto M, et al. Immune modulation by telomerase-specific oncolytic adenovirus synergistically enhances antitumor efficacy with anti-PD1 antibody. Mol Ther. 2020;28(3):794-804.

257. Yang Y, Xu W, Peng D, Wang H, Zhang X, Wang H, et al. An oncolytic adenovirus targeting transforming growth factor $\beta$ inhibits protumorigenic signals and produces immune activation: a novel approach to enhance anti-PD-1 and anti-CTLA-4 therapy. Hum Gene Ther. 2019:30(9):1117-32.

258. Gartrell RD, Blake Z, Esancy CL, Perez-Lorenzo R, Rizk E, Fu Y, et al. Effect of combination immunotherapy on tumor growth, survival, and intratumoral immune infiltration in transgenic murine model of melanoma. Am Soc Clin Oncol. 2018;36:e21610.

259. Kos S, Lopes A, Preat V, Cemazar M, Lampreht Tratar U, Ucakar B, et al. Intradermal DNA vaccination combined with dual CTLA-4 and PD-1 blockade provides robust tumor immunity in murine melanoma. PLoS ONE. 2019;14(5):e0217762.

260. Nair S, Mazzoccoli L, Jash A, Govero J, Bais SS, Hu T, et al. Zika virus oncolytic activity requires $C D 8+T$ cells and is boosted by immune checkpoint blockade. JCI Insight. 2021:6(1).

261. Chen CY, Wang PY, Hutzen B, Sprague L, Swain HM, Love JK, et al. Cooperation of oncolytic herpes virotherapy and PD-1 blockade in murine rhabdomyosarcoma models. Sci Rep. 2017;7(1):2396

262. Du W, Seah I, Bougazzoul O, Choi G, Meeth K, Bosenberg MW, et al. Stem cell-released oncolytic herpes simplex virus has therapeutic efficacy in brain metastatic melanomas. Proc Natl Acad Sci. 2017:114(30):E6157-65.

263. Stark FC, Weeratna RD, Deschatelets L, Gurnani K, Dudani R, McCluskie $\mathrm{MJ}$, et al. An archaeosome-adjuvanted vaccine and checkpoint inhibitor therapy combination significantly enhances protection from murine melanoma. Vaccines. 2017:5(4):38

264. Lin PL, Cheng YM, Wu DW, Huang YJ, Lin HC, Chen CY, et al. A combination of anti-PD-L1 mAb plus Lm-LLO-E6 vaccine efficiently suppresses tumor growth and metastasis in HPV-infected cancers. Cancer Med. 2017;6(9):2052-62.

265. Jiang H, Rivera-Molina Y, Gomez-Manzano C, Clise-Dwyer K, Bover L, Vence LM, et al. Oncolytic adenovirus and tumor-targeting immune modulatory therapy improve autologous cancer vaccination. Can Res. 2017;77(14):3894-907

266. Cappuccini F, Stribbling S, Pollock E, Hill AV, Redchenko I. Immunogenicity and efficacy of the novel cancer vaccine based on simian adenovirus and MVA vectors alone and in combination with PD-1 mAb in a mouse model of prostate cancer. Cancer Immunol Immunother. 2016;65(6):701-13.

267. Dorta-Estremera S, Chin RL, Sierra G, Nicholas C, Yanamandra AV, Nookala SM, et al. Mucosal HPV E6/E7 peptide vaccination in combination with immune checkpoint modulation induces regression of HPV+ oral cancers. Can Res. 2018;78(18):5327-39.

268. Rajani K, Parrish C, Kottke T, Thompson J, Zaidi S, llett L, et al. Combination therapy with reovirus and anti-PD-1 blockade controls tumor growth through innate and adaptive immune responses. Mol Ther. 2016;24(1):166-74.

269. Samson A, Scott KJ, Taggart D, West EJ, Wilson E, Nuovo GJ, et al. Intravenous delivery of oncolytic reovirus to brain tumor patients immunologically primes for subsequent checkpoint blockade. Sci Transl Med. 2018;10(422)

270. Cappuccini F, Pollock E, Stribbling S, Hill AV, Redchenko I. 5 T4 oncofoetal glycoprotein: an old target for a novel prostate cancer immunotherapy. Oncotarget. 2017:8(29):47474.

271. Stark FC, Agbayani G, Sandhu JK, Akache B, McPherson C, Deschatelets $L$, et al. Simplified admix archaeal glycolipid adjuvanted vaccine and checkpoint inhibitor therapy combination enhances protection from murine melanoma. Biomedicines. 2019;7(4):91.

272. Engeland CE, Grossardt C, Veinalde R, Bossow S, Lutz D, Kaufmann JK, et al. CTLA-4 and PD-L1 checkpoint blockade enhances oncolytic measles virus therapy. Mol Ther. 2014;22(11):1949-59.

273. Simons BW, Cannella F, Rowley DT, Viscidi RP. Bovine papillomavirus prostate cancer antigen virus-like particle vaccines are efficacious in advanced cancers in the TRAMP mouse spontaneous prostate cancer model. Cancer Immunol Immunother. 2020;69(4):641-51. 
274. Li Z, Wang Y, Shen Y, Qian C, Oupicky D, Sun M. Targeting pulmonary tumor microenvironment with CXCR4-inhibiting nanocomplex to enhance anti-PD-L1 immunotherapy. Sci Adv. 2020;6(20):eaaz9240.

275. Wu A, Cardarelli P, Oyasu M, Menezes D, Ponath P, Cogswell J, et al. The combination of CXCR4 and checkpoint receptor inhibition improves survival in an orthotopic murine glioma model. AACR; 2018.

276. Zhou M, Luo C, Zhou Z, Li L, Huang Y. Improving anti-PD-L1 therapy in triple negative breast cancer by polymer-enhanced immunogenic cell death and CXCR4 blockade. J Control Release. 2021;334:248-62.

277. Andtbacka R, Pierce RH, Campbell JS, Yushak M, Milhem M, Ross MI, et al. X4P-001, an orally bioavailable CXCR4 antagonist, enhances immune cell infiltration and activation in the tumor microenvironment of melanoma. RNA (Normalized Counts). 2018;400:200.

278. Li Q, Wang Y, Jia W, Deng H, Li G, Deng W, et al. Low-dose anti-angiogenic therapy sensitizes breast cancer to PD-1 blockade. Clin Cancer Res. 2020;26(7):1712-24.

279. Wallin JJ, Bendell JC, Funke R, Sznol M, Korski K, Jones S, et al. Atezolizumab in combination with bevacizumab enhances antigen-specific T-cell migration in metastatic renal cell carcinoma. Nat Commun. 2016;7:12624

280. Hodi FS, Lawrence D, Lezcano C, Wu X, Zhou J, Sasada T, et al. Bevacizumab plus ipilimumab in patients with metastatic melanoma. Cancer Immunol Res. 2014;2(7):632-42.

281. Amin A, Plimack ER, Ernstoff MS, Lewis LD, Bauer TM, McDermott DF, et al. Safety and efficacy of nivolumab in combination with sunitinib or pazopanib in advanced or metastatic renal cell carcinoma: the CheckMate 016 study. J Immunother Cancer. 2018:6(1):109.

282. Antoniotti C, Borelli B, Rossini D, Pietrantonio F, Morano F, Salvatore $L$, et al. AtezoTRIBE: a randomised phase II study of FOLFOXIRI plus bevacizumab alone or in combination with atezolizumab as initial therapy for patients with unresectable metastatic colorectal cancer. BMC Cancer. 2020;20(1):683.

283. Wu X, Li J, Connolly EM, Liao X, Ouyang J, Giobbie-Hurder A, et al. Combined anti-VEGF and anti-CTLA-4 therapy elicits humoral immunity to galectin-1 which is associated with favorable clinical outcomes. Cancer Immunol Res. 2017;5(6):446-54.

284. Martin-Broto J, Hindi N, Grignani G, Martinez-Trufero J, Redondo A, Valverde $C$, et al. Nivolumab and sunitinib combination in advanced soft tissue sarcomas: a multicenter, single-arm, phase Ib/ll trial. J Immunother Cancer. 2020:8(2):001561.

285. Chu T, Zhong R, Zhong H, Zhang B, Zhang W, Shi C, et al. Phase $1 \mathrm{~b}$ study of sintilimab plus anlotinib as first-line therapy in patients with advanced NSCLC. J Thorac Oncol. 2021;16(4):643-52.

286. Taylor MH, Lee CH, Makker V, Rasco D, Dutcus CE, Wu J, et al. Phase IB/ Il trial of lenvatinib plus pembrolizumab in patients with advanced renal cell carcinoma, endometrial cancer, and other selected advanced solid tumors. J Clin Oncol. 2020;38(11):1154-63.

287. Choueiri TK, Powles T, Burotto M, Escudier B, Bourlon MT, Zurawski $B$, et al. Nivolumab plus cabozantinib versus sunitinib for advanced renal-cell carcinoma. N Engl J Med. 2021;384(9):829-41.

288. Sakamuri D, Glitza IC, Betancourt Cuellar SL, Subbiah V, Fu S, Tsimberidou AM, et al. Phase I dose-escalation study of anti-CTLA-4 antibody ipilimumab and lenalidomide in patients with advanced cancers. Mol Cancer Ther. 2018;17(3):671-6.

289. Sugawara S, Lee JS, Kang JH, Kim HR, Inui N, Hida T, et al. Nivolumab with carboplatin, paclitaxel, and bevacizumab for first-line treatment of advanced nonsquamous non-small-cell lung cancer. Ann Oncol. 2021:32(9):1137-47.

290. Paz-Ares L, Ciuleanu TE, Cobo M, Schenker M, Zurawski B, Menezes $J$, et al. First-line nivolumab plus ipilimumab combined with two cycles of chemotherapy in patients with non-small-cell lung cancer (CheckMate 9LA): an international, randomised, open-label, phase 3 trial. Lancet Oncol. 2021;22(2):198-211.

291. Peng M, Li X, Lei G, Weng YM, Hu MX, Song QB. The efficacy and safety of immune checkpoint inhibitor combination therapy in lung cancer: a systematic review and meta-analysis. Onco Targets Ther. 2018;11:7369.

292. Lynch TJ, Bondarenko I, Luft A, Serwatowski P, Barlesi F, Chacko R, et al. Ipilimumab in combination with paclitaxel and carboplatin as first-line treatment in stage IIIB/IV non-small-cell lung cancer: results from a randomized, double-blind, multicenter phase II study. J Clin Oncol. 2012;30(17):2046-54.

293. Ikushima H, Sakatani T, Ohara S, Takeshima H, Horiuchi H, Morikawa $\mathrm{T}$, et al. Cisplatin plus pemetrexed therapy and subsequent immune checkpoint inhibitor administration for malignant peritoneal mesothelioma without pleural lesions: case report. Medicine. 2020;99(22):e19956.

294. Kamath SD, Kalyan A, Kircher S, Nimeiri H, Fought AJ, Benson A III, et al. Ipilimumab and gemcitabine for advanced pancreatic cancer: a phase lb study. Oncologist. 2020;25(5):e808.

295. Wainberg ZA, Hochster HS, Kim EJ-H, George B, Kalyan A, Chiorean EG, et al. Phase I study of nivolumab (Nivo)+ nab-paclitaxel (nab-P)+ gemcitabine (Gem) in advanced pancreatic cancer (APC). Am Soc Clin Oncol. 2019;37:298.

296. Lara P, Beckett L, Li Y, Parikh M, Robles D, Aujla P, et al. Combination checkpoint immunotherapy and cytotoxic chemotherapy: pembrolizumab (Pembro) plus either docetaxel or gemcitabine in patients with advanced or metastatic urothelial cancer. Am Soc Clin Oncol. 2017;35:398.

297. Yamazaki N, Uhara H, Fukushima S, Uchi H, Shibagaki N, Kiyohara Y, et al. Phase II study of the immune-checkpoint inhibitor ipilimumab plus dacarbazine in Japanese patients with previously untreated, unresectable or metastatic melanoma. Cancer Chemother Pharmacol. 2015;76(5):969-75.

298. Postow MA, Callahan MK, Barker CA, Yamada Y, Yuan J, Kitano S, et al. Immunologic correlates of the abscopal effect in a patient with melanoma. N Engl J Med. 2012:366(10):925-31.

299. Hiniker SM, Chen DS, Reddy S, Chang DT, Jones JC, Mollick JA, et al. A systemic complete response of metastatic melanoma to local radiation and immunotherapy. Transl Oncol. 2012;5(6):404-7.

300. Slovin S, Higano C, Hamid O, Tejwani S, Harzstark A, Alumkal J, et al. Ipilimumab alone or in combination with radiotherapy in metastatic castration-resistant prostate cancer: results from an open-label, multicenter phase I/II study. Ann Oncol. 2013;24(7):1813-21.

301. Levy A, Massard C, Soria J-C, Deutsch E. Concurrent irradiation with the anti-programmed cell death ligand-1 immune checkpoint blocker durvalumab: single centre subset analysis from a phase $1 / 2$ trial. Eur J Cancer. 2016:68:156-62

302. Puzanov I, Milhem MM, Minor D, Hamid O, Li A, Chen L, et al. Talimogene laherparepvec in combination with ipilimumab in previously untreated, unresectable stage IIIB-IV melanoma. J Clin Oncol. 2016:34(22):2619.

303. Chesney J, Puzanov I, Collichio F, Singh P, Milhem MM, Glaspy J, et al. Randomized, open-label phase II study evaluating the efficacy and safety of talimogene laherparepvec in combination with ipilimumab versus ipilimumab alone in patients with advanced, unresectable melanoma. J Clin Oncol. 2018;36(17):1658.

304. Scholz M, Yep S, Chancey M, Kelly C, Chau K, Turner J, et al. Phase I clinical trial of sipuleucel-T combined with escalating doses of ipilimumab in progressive metastatic castrate-resistant prostate cancer. ImmunoTargets Ther. 2017;6:11.

305. Madan RA, Mohebtash M, Arlen PM, Vergati M, Rauckhorst M, Steinberg SM, et al. Ipilimumab and a poxviral vaccine targeting prostate-specific antigen in metastatic castration-resistant prostate cancer: a phase 1 dose-escalation trial. Lancet Oncol. 2012;13(5):501-8.

306. Gerritsen W, Van Den Eertwegh A, De Gruijl T, van den Berg H, Scheper R, Sacks N, et al. Expanded phase I combination trial of GVAX immunotherapy for prostate cancer and ipilimumab in patients with metastatic hormone-refractory prostate cancer (mHPRC). J Clin Oncol. 2008:26(15_suppl):5146.

307. Attia P, Phan GQ, Maker AV, Robinson MR, Quezado MM, Yang JC, et al. Autoimmunity correlates with tumor regression in patients with metastatic melanoma treated with anti-cytotoxic T-lymphocyte antigen-4. J Clin Oncol. 2005:23(25):6043.

308. Hodi FS, O'Day SJ, McDermott DF, Weber RW, Sosman JA, Haanen JB, et al. Improved survival with ipilimumab in patients with metastatic melanoma. N Engl J Med. 2010;363(8):711-23.

309. Blake Z, Marks DK, Gartrell RD, Hart T, Horton P, Cheng SK, et al. Complete intracranial response to talimogene laherparepvec (T-Vec), pembrolizumab and whole brain radiotherapy in a patient with 
melanoma brain metastases refractory to dual checkpoint-inhibition. J Immunother Cancer. 2018;6(1):1-8.

310. Afzal MZ, Shirai K. Response to the rechallenge with Talimogene Laherparepvec (T-VEC) after Ipilimumab/Nivolumab treatment in patient with cutaneous malignant melanoma who initially had a progression on T-VEC with pembrolizumab. J Immunother. 2019;42(4):136-41.

311. Tsujikawa T, Crocenzi T, Durham JN, Sugar EA, Wu AA, Onners B, et al. Evaluation of cyclophosphamide/GVAX pancreas followed by Listeriamesothelin (CRS-207) with or without nivolumab in patients with pancreatic cancer. Clin Cancer Res. 2020;26(14):3578-88.

312. Le DT, Crocenzi TS, Urum JN, Lutz ER, Laheru DA, Sugar EA, et al. Randomized Phase II study of the safety, efficacy and immune response of GVAX pancreas (with cyclophosphamide) and CRS-207 with or without nivolumab in patients with previously treated metastatic pancreatic adenocarcinoma (STELLAR). J Immunother Cancer. 2015;3(2):P155.

313. Gibney GT, Weber JS, Kudchadkar RR, De Conti RC, Tetteh L, Eysmans C, et al. Safety and efficacy of adjuvant anti-PD1 therapy (nivolumab) in combination with vaccine in resected high-risk metastatic melanoma. Am Soc Clin Oncol. 2013;31:9056.

314. Zimmer AS, Nichols E, Cimino-Mathews A, Peer C, Cao L, Lee M-J, et al. A phase I study of the PD-L1 inhibitor, durvalumab, in combination with a PARP inhibitor, olaparib, and a VEGFR1-3 inhibitor, cediranib, in recurrent women's cancers with biomarker analyses. J Immunother Cancer. 2019;7(1):1-8.

315. Lampert EJ, Zimmer A, Padget M, Cimino-Mathews A, Nair JR, Liu Y, et al. Combination of PARP inhibitor olaparib, and PD-L1 inhibitor durvalumab, in recurrent ovarian cancer: a proof-of-concept phase II study. Clin Cancer Res. 2020;26(16):4268-79.

316. Zaemes J, Alzeer A, Villa K, Atkins M. A patient with melanoma that became sensitized to immunotherapy after treatment with a CDK4/6 inhibitor. Immunotherapy. 2020;12(12):861-7.

\section{Publisher's Note}

Springer Nature remains neutral with regard to jurisdictional claims in published maps and institutional affiliations.

- fast, convenient online submission

- thorough peer review by experienced researchers in your field

- rapid publication on acceptance

- support for research data, including large and complex data types

- gold Open Access which fosters wider collaboration and increased citations

- maximum visibility for your research: over $100 \mathrm{M}$ website views per year

At BMC, research is always in progress.

Learn more biomedcentral.com/submissions 